OAK RIDGE

NATIONAL LABORATORY

ORNL/TM-2014/1

MANAGED BY UT-BATTELLE

FOR THE DEPARTMENT OF ENERGY

\title{
Ex-Vessel Core Melt Modeling Comparison between MELTSPREAD- CORQUENCH and MELCOR 2.1
}

March 2014

Prepared by

Kevin R. Robb and Matthew W. Francis

Oak Ridge National Laboratory

Mitchell T. Farmer

Argonne National Laboratory

Approved for public release;

distribution is unlimited.

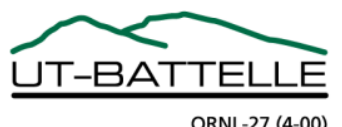




\section{DOCUMENT AVAILABILITY}

Reports produced after January 1, 1996, are generally available free via US Department of Energy (DOE) SciTech Connect.

Website http://www.osti.gov/scitech/

Reports produced before January 1, 1996, may be purchased by members of the public from the following source:

National Technical Information Service

5285 Port Royal Road

Springfield, VA 22161

Telephone 703-605-6000 (1-800-553-6847)

TDD 703-487-4639

Fax 703-605-6900

E-mail info@ntis.gov

Website http://www.ntis.gov/support/ordernowabout.htm

Reports are available to DOE employees, DOE contractors, Energy Technology Data Exchange representatives, and International Nuclear Information System representatives from the following source:

Office of Scientific and Technical Information

PO Box 62

Oak Ridge, TN 37831

Telephone 865-576-8401

Fax 865-576-5728

E-mail reports@osti.gov

Website http://www.osti.gov/contact.html

This report was prepared as an account of work sponsored by an agency of the United States Government. Neither the United States Government nor any agency thereof, nor any of their employees, makes any warranty, express or implied, or assumes any legal liability or responsibility for the accuracy, completeness, or usefulness of any information, apparatus, product, or process disclosed, or represents that its use would not infringe privately owned rights. Reference herein to any specific commercial product, process, or service by trade name, trademark, manufacturer, or otherwise, does not necessarily constitute or imply its endorsement, recommendation, or favoring by the United States Government or any agency thereof. The views and opinions of authors expressed herein do not necessarily state or reflect those of the United States Government or any agency thereof. 
Reactor and Nuclear Systems Division

\title{
EX-VESSEL CORE MELT MODELING COMPARISON BETWEEN MELTSPREAD-CORQUENCH AND MELCOR 2.1
}

\author{
Kevin R. Robb, Ph.D. \\ Matthew W. Francis, Ph.D. \\ Oak Ridge National Laboratory \\ Mitchell T. Farmer, Ph.D. \\ Argonne National Laboratory
}

Date Published: March 2014

\author{
Prepared by \\ OAK RIDGE NATIONAL LABORATORY \\ Oak Ridge, Tennessee 37831-6283 \\ managed by \\ UT-BATTELLE, LLC \\ for the \\ U.S. DEPARTMENT OF ENERGY \\ under contract DE-AC05-00OR22725
}





\section{CONTENTS}

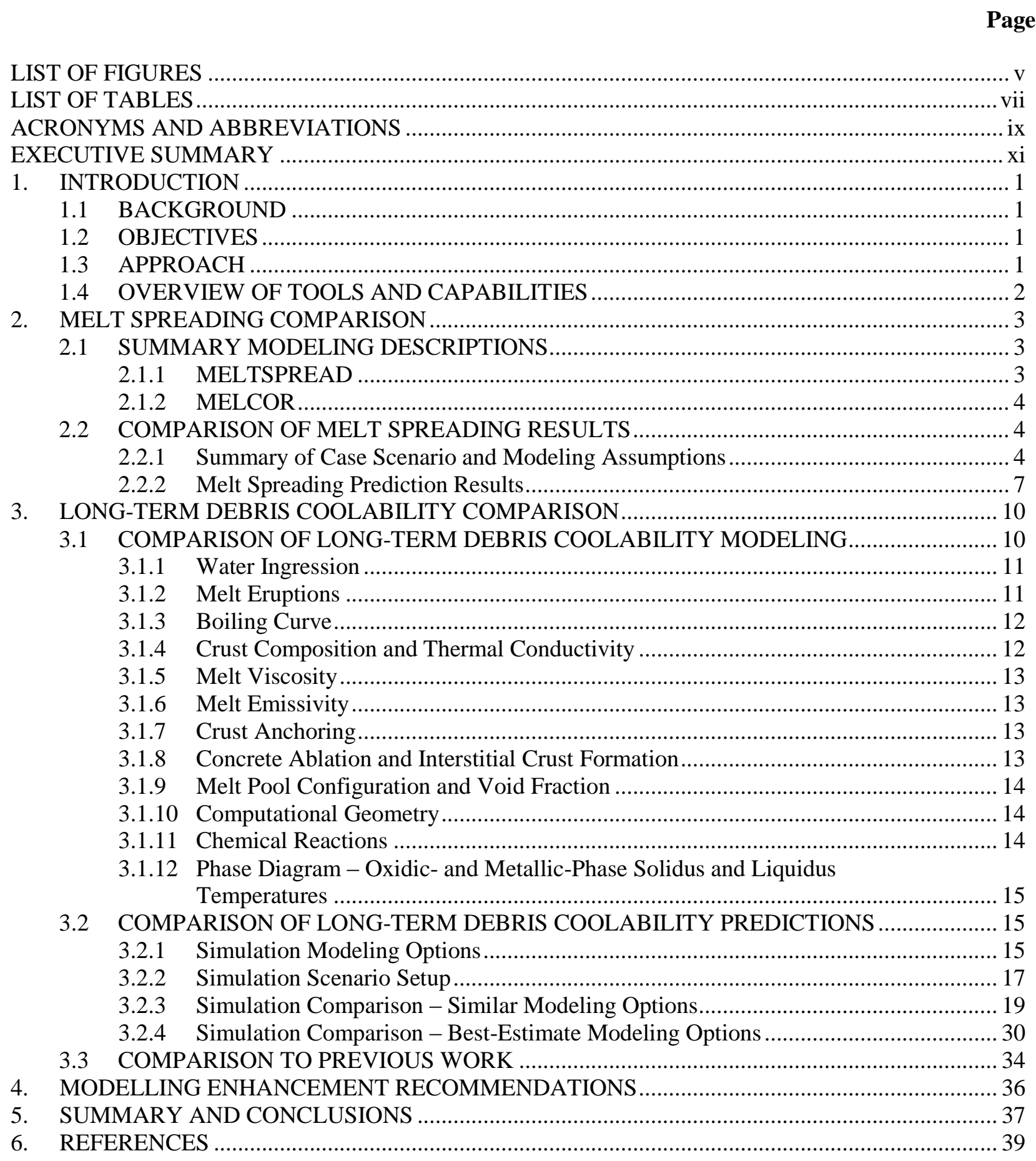





\section{LIST OF FIGURES}

Page

Fig. 1. Cumulative core debris discharge from RPV for MELCOR Sequence [1] ................................... 6

Fig. 2. Comparison of MELTSPREAD and MELCOR floor coverage predictions during spreading......... 8

Fig. 3. MELTSPREAD predictions of leading edge penetration during spreading in the $1 \mathrm{~F} 1$ and

Peach Bottom pedestal and drywell regions...................................................................... 8

Fig. 4. MELTSPREAD predictions of melt depth adjacent to the drywell liner for the 1F1 and

Peach Bottom containment geometries.

Fig. 5. Concrete ablation profile at $0,2,12$ and 48 hours after melt-concrete contact;

CORQUENCH shown using dashed lines; MELCOR shown using solid lines.

Fig. 6. Radial and axial concrete ablation fronts.............................................................................. 22

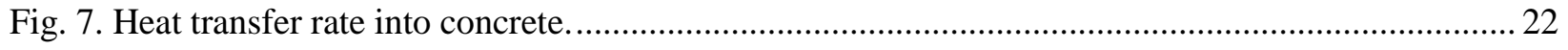

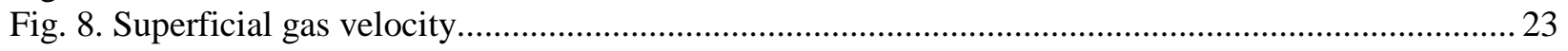

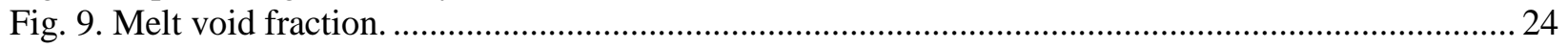

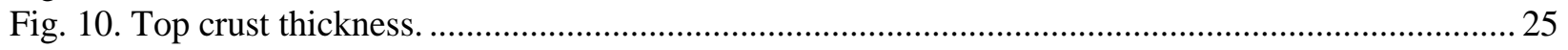

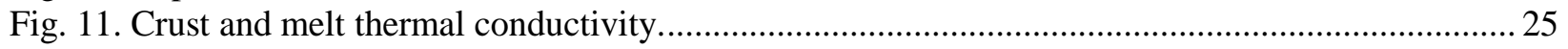

Fig. 12. MELCOR predicted side and bottom crust thicknesses. ...................................................... 26

Fig. 13. Melt pool metallic species evolution, (A, B) CORQUENCH, (C, D) MELCOR...................... 27

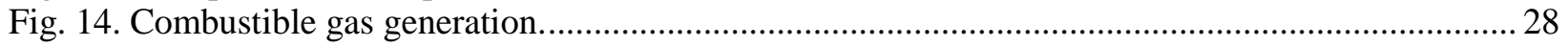

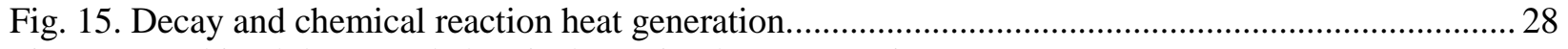

Fig. 16. Combined decay and chemical reaction heat generation...........................................................29

Fig. 17. Predicted bulk melt temperature, (A) CORQUENCH, (B) MELCOR ........................................ 29

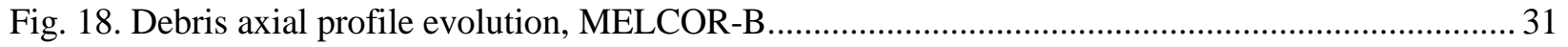

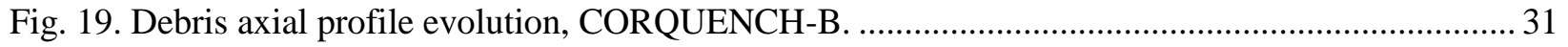

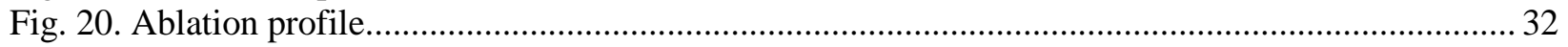

Fig. 21. Debris axial profile evolution, refined plot scale, CORQUENCH-B ..................................... 33

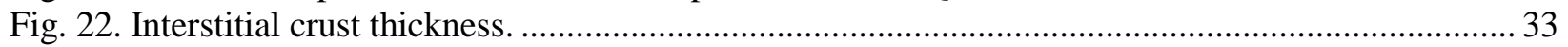

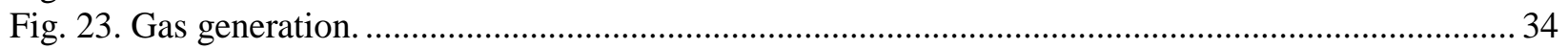





\section{LIST OF TABLES}

Page

Table 1. Melt spreading input data from MELCOR $[1,8]$ accident analyses ........................................... 5

Table 2. Comparison of 1F1 and Peach Bottom containment geometries .............................................. 7

Table 3. Summary of MELCOR v2.1 (CORCON-Mod3) and CORQUENCH v3.03 phenomena ............. 10

Table 4. Summary of modeling options and parameters for coolability simulations ............................... 16

Table 5. Basaltic concrete composition assumed in analyses (CORCON Mod3 basalt [12]) .................. 18

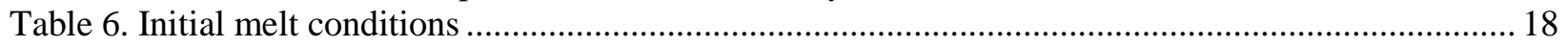

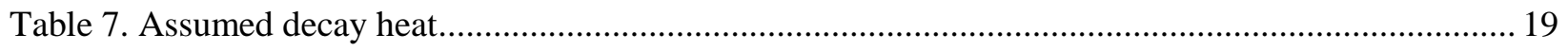

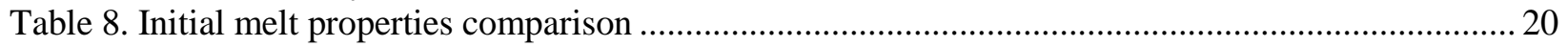





\section{ACRONYMS AND ABBREVIATIONS}

1F1

ANL

DOE-NE

EPR

MACE

MCCI

NEA

NRC

OECD

RPV

SIL
Fukushima Daiichi Unit 1

Argonne National Laboratory

Department of Energy: Office of Nuclear Energy

European Pressurized Reactor

Melt Attack and Coolability Experiment

molten corium-concrete interaction

Nuclear Energy Agency

Nuclear Regulatory Commission

Organization for Economic Cooperation and Development

reactor pressure vessel

Siliceous-type concrete 



\section{EXECUTIVE SUMMARY}

System-level code analyses by both United States and international researchers predict major core melting, bottom head failure, and corium-concrete interaction for Fukushima Daiichi Unit 1 (1F1). Although system codes such as MELCOR and MAAP are capable of capturing a wide range of accident phenomena, they currently do not contain detailed models for evaluating some ex-vessel core melt behavior. However, specialized codes containing more detailed modeling are available for melt spreading — such as MELTSPREAD — as well as long-term molten corium-concrete interaction (MCCI) and debris coolability - such as CORQUENCH.

In a preceding study, Enhanced Ex-Vessel Analysis for Fukushima Daiichi Unit 1: Melt Spreading and Core-Concrete Interaction Analyses with MELTSPREAD and CORQUENCH, the MELTSPREADCORQUENCH codes predicted the $1 \mathrm{~F} 1$ core melt readily cooled in contrast to predictions by MELCOR. The user community has taken notice and is in the process of updating their systems codes; specifically MAAP and MELCOR, to improve and reduce conservatism in their ex-vessel core melt models.

This report investigates why the MELCOR v2.1 code, compared to the MELTSPREAD and CORQUENCH 3.03 codes, yield differing predictions of ex-vessel melt progression. To accomplish this, the differences in the treatment of the ex-vessel melt with respect to melt spreading and long-term coolability are examined. The differences in modeling approaches are summarized, and a comparison of example code predictions is provided.

Regarding melt spreading, MELTSPREAD includes relatively detailed modeling of core debris relocation including fluid-mechanics effects, heat transfer to overlying water and underlying concrete, and finally mechanistically calculated solidification at the debris leading edge. In contrast, the MELCOR code predicts the melt spread area through the use of a mass balance and a user-specified hydraulic relationship which spreads the melt based on the melt height and temperature. Despite the major differences in modeling approaches, the overall differences in predicted spreading behavior between the two codes are not that large; that is, MELCOR predicts melt accumulation and spreading out of the pedestal doorway at 194 seconds, whereas MELTSPREAD predicts earlier penetration into the drywell at 98 seconds. By the end of the spreading transient, MELCOR predicts $38 \mathrm{~m}^{2}$ of total floor area coverage, which is $21 \%$ more than MELTSPREAD (i.e., $31.4 \mathrm{~m}^{2}$ ). Although agreement for this particular 1F1 sequence is reasonable, it is not clear from this study how well the two codes would compare under a different set of conditions such as a hotter or colder melt release.

Regarding modeling of long-term core-concrete interaction behavior and debris coolability, MELCOR and CORQUENCH share many common elements, but deviate in the following areas: (i) MELCOR has a sophisticated cavity profile erosion model, whereas CORQUENCH uses a highly simplified 2-D cavity profile model; (ii) the MELCOR metal oxidation models are more sophisticated in comparison to CORQUENCH; and (iii) MELCOR does not currently contain debris cooling models that can calculate quench and thermal stabilization of core debris following cavity flooding; in contrast, CORQUENCH includes relatively sophisticated models for calculating core debris cooling by melt eruption and water ingression cooling mechanisms. The two codes were applied under a similar set of modeling conditions to the $1 \mathrm{~F} 1$ sump configuration (i.e., quasi-steady concrete ablation models invoked with no melt coolability models invoked). Under these conditions, the two codes were found to produce quite similar trends in cavity erosion behavior after 48 hours. The differences are primarily related to the way in which condensed-phase chemical reactions between cladding and silica materials arising from core-concrete interaction are treated. It is important to note that with melt coolability models disabled, both codes predict ongoing core-concrete interaction after 48 hours with eventual basemat penetration. With coolability models invoked, CORQUENCH predicts relatively rapid debris quenching and stabilization of the core debris in the 1F1 sump after approximately 150 minutes. In contrast, MELCOR, even with heat transfer enhancements (increasing boiling curve and melt and crust thermal conductivity), predicts continued concrete erosion in the $1 \mathrm{~F} 1 \mathrm{sump}$. 
Finally, based on a comparison of the codes a number of updates were identified and recommended. It is recommended that models for water ingression, melt eruption, and crust anchoring be added to MELCOR. For use in developing a spreading model, it would be useful to the MELCOR user if the melt properties, such as the solidus and liquidus temperatures, were accessible. Adding the ability in MELCOR to independently track the composition of the top, bottom and side crusts would facilitate more accurate prediction of the crust thicknesses and related heat transfer. Adding a melt stream breakup model through water to MELTSPREAD, to be used during melt relocation, would provide for more accurate determination of the extent of melt spreading and post-spreading debris depth important with respect to long-term debris coolability. It is recommended to expand the treatment of chemical reactions in CORQUENCH to include the oxidation of elemental silicon and nickel. Finally, it was found that differences in containment designs between Peach Bottom and 1F1 had an effect on melt spreading and likely the debris cooling in the sumps. Therefore, it is recommended that the actual containment characteristics of $1 \mathrm{~F} 1$ be taken into account in future modeling activities. 


\section{INTRODUCTION}

\subsection{BACKGROUND}

The MELCOR code simulations for Fukushima Daiichi Unit 1 (1F1), carried out as a part of a joint effort between the Office of Nuclear Energy within the Department of Energy (DOE-NE) and the Nuclear Regulatory Commission (NRC) Fukushima Daiichi Accident Study [1], predict major core melting, bottom head failure, and corium-concrete interaction. These predictions are in agreement with simulations performed by the Electric Power Research Institute using the MAAP code [2], as well as the Japanese Nuclear Energy Safety Organization using MELCOR [3] and the Tokyo Electric Power Company using MAAP $[3,4]$.

Both MELCOR and MAAP are capable systems-level modeling tools that capture a wide spectrum of accident phenomena in a tractable manner. However, for ex-vessel sequences, specialized codes containing more detailed modeling are available for the analysis of melt spreading such as MELTSPREAD [5,6], as well as debris coolability during molten corium-concrete interaction (MCCI) such as CORQUENCH [7]. On this basis, the DOE-NE funded an analysis to further evaluate the exvessel core debris location and extent of interaction for 1F1 using modern modeling and simulation tools. This study was documented as Enhanced Ex-Vessel Analysis for Fukushima Daiichi Unit 1: Melt Spreading and Core-Concrete Interaction Analyses with MELTSPREAD and CORQUENCH [8]. This study was useful as it showed that, contrary to MELCOR predictions, the 1F1 core melt readily quenched and the results conformed to physical observations (i.e. the low/negligible long term hydrogen concentration in containment). Based on this, the user community is in the process of updating their system level codes; specifically MAAP [9] and MELCOR [10, 11], to improve and reduce conservatism in their ex-vessel core melt models.

This second study answers "why" the MELTSPREAD and CORQUENCH codes more accurately predict the ex-vessel progression than MELCOR. This is accomplished by comparing the detailed modeling methods employed in the MELTSPREAD and CORQUENCH codes to those employed in the MELCOR code. The following study compares the key models utilized and sample simulation results for the codes.

\subsection{OBJECTIVES}

The high-level objective of this work is to compare the modeling methodologies integrated into the MELTSPREAD and CORQUENCH codes to those used in MELCOR with respect to ex-vessel melt spreading and long-term debris coolability. The impact of the identified code differences is illustrated by comparing simulation predictions from the codes. The Fukushima Daiichi Unit 1 reactor serves as a basis for the simulation comparisons. As a result of this study, key areas for code improvements may be identified. This study will also provide insight into reviewing and interpreting ex-vessel results from current and past MELCOR analyses. Finally, this work is intended to support ongoing forensic modeling efforts related to the accident sequence and flammable gas generation.

\subsection{APPROACH}

Given best-estimate melt pour conditions following reactor pressure vessel (RPV) failure based on MELCOR [1] and MAAP [2] analyses of the Unit 1 accident sequence, MELTSPREAD was used to predict the time-dependent melt spreading, basemat attack, zirconium and other metal oxidation (viz., combustible gas production), debris cooling, and drywell liner attack during the transient spreading phase [8].

One of the principal outcomes of the past analysis was the rate and extent of floor coverage during spreading. Thus, the first part of this study focuses on directly comparing the MELCOR and MELTSPREAD predictions of ex-vessel core melt spreading behavior in 1F1. Since the ex-vessel 
geometry assumed in the MELCOR analyses for 1F1 was actually equivalent to the Peach Bottom geometry [1], an additional MELTSPREAD case was run using this plant geometry so that the MELCOR and MELTSPREAD results could be directly compared.

Another principal outcome of the past analysis was the duration and extent of concrete ablation by the molten core debris. Thus, the second part of this study focuses on directly comparing the MELCOR and CORQUENCH predictions of the long-term ex-vessel molten core-concrete interaction behavior in 1F1. Since the ex-vessel geometry assumed in the MELCOR analyses for 1F1 was actually equivalent to the Peach Bottom geometry [1], additional MELCOR simulations were run using the 1F1 plant geometry so that the MELCOR and CORQUENCH results could be directly compared. First, a cross-comparison of models used by the codes is discussed. Next, a comparison is performed for simulation results where both codes used similar modeling options. This was to show whether under similar modeling assumptions, the two codes predict similar results. Next a comparison was made between the codes using their bestestimate models and parameters.

\subsection{OVERVIEW OF TOOLS AND CAPABILITIES}

The MCCI modeling capability of MELCOR v2.1 is based on CORCON-Mod3 [12]. Since the development of that code, a number of international research programs and experiments have been conducted (MACE, OECD/NEA MCCI-1, and MCCI-2 [13]). Insights and models from these research activities have been integrated into the CORQUENCH code; however, they have not been integrated into CORCON/MELCOR to date. Phenomena accounted for in CORQUENCH that are not currently in MELCOR (e.g., crust anchoring and debris cooling by water ingression and melt eruption mechanisms) are known to have potentially large impacts on MCCI progression [13]. The CORQUENCH code is able to evaluate melt debris coolability and the axial and radial ablation of concrete due to MCCI. In the event that the debris does not quench, the code predicts melt penetration through the containment liner. The code also predicts the amount of gases liberated from the decomposing concrete, oxidation of the melt debris, and steam generated from any water cooling. These processes impact containment failure through pressurization and possible $\mathrm{H}_{2} / \mathrm{CO}$ deflagration or detonation. MELCOR predicts all of the same phenomena with the exception of debris coolability. In particular, MELCOR currently assumes that a conduction-limited crust forms at the melt-water interface, and that this crust is impervious to any form of water ingression. Thus, MELCOR predicts ongoing melt-concrete interaction even after cavity flooding and eventual basemat penetration by MCCI.

The MELCOR code predicts the melt spread area through use of a mass balance and a basic empirical hydraulic relationship which spreads the melt based on the melt height and temperature [1]. The code does not currently take into account viscosity or leading-edge freezing effects, which are key physics to the spread process. Thus, there is a high degree of uncertainty in the melt spread area predicted by MELCOR. In contrast, MELTSPREAD calculates the area over which the melt spreads, taking into account a number of physical phenomena including varying melt viscosity, heat transfer, and solidification at the leading edge of the spreading melt. In addition to predicting the lateral spread of the melt, MELTSPREAD has the ability to predict melt-liner attack and failure of the liner if the melt is predicted to contact the drywell liner (near the floor). This capability provides a means to investigate the potential for this failure mode as an alternative to the containment head-lifting scenario for $1 \mathrm{~F} 1$ predicted by MELCOR [1]. 


\section{MELT SPREADING COMPARISON}

\subsection{SUMMARY MODELING DESCRIPTIONS}

The following sections compare the modeling methodologies and phenomena accounted for in the MELTSPREAD and MELCOR codes with respect to predicting ex-vessel melt spreading.

\subsubsection{MELTSPREAD}

MELTSPREAD was originally developed to support resolution of the Mark I shell vulnerability issue [6]. Given the time-dependent core melt pour conditions (i.e., temperature, composition, and flowrate) from the reactor pressure vessel, the code solves the one-dimensional momentum equation to evaluate melt spreading depth and velocity while accounting for local core debris cooldown and solidification, concrete heatup and decomposition, metals oxidation from concrete decomposition gases, and heat transfer to overlying atmosphere under both wet and dry cavity conditions. The code was developed to treat a wide range of melt compositions ranging from fully metallic to fully oxidic. In addition, the code has the ability to calculate heatup of a structure adjacent to (or in the pathway of) flowing core debris. This model was specifically developed to examine heatup of the Mark I shell under conditions in which the core debris was calculated to make contact with that structure.

MELTSPREAD was recently updated and extensively validated for application to spreading in the European Pressurized Reactor (EPR) core catcher design [14]. For that effort, several improvements to the code were made in order to validate the code over a full range of melt spreading data involving heat transfer and solidification. In particular, the melt property subroutines in the original code were only capable of treating mixtures of core and cladding metals and their corresponding oxides, and only substrates composed of concrete, steel, or an arbitrary combination thereof. Thus, one of the first improvements was to provide the ability to input simulant melt and/or substrate material properties (density, thermal conductivity, solid/liquid-phase specific heats, heat of fusion, emissivity). This allowed all "simulant oxide" tests identified in the literature to be calculated, as well as tests with ceramic substrate, using property data that was in almost all cases provided by the institutions who carried out the experiments. The ability to overwrite selected melt material properties was also added for sensitivity analysis.

Another key modeling improvement in the area of material properties was providing the ability to input a tabular function for the oxide-phase solid fraction variation between the liquidus and solidus temperatures. The original version of the code assumed that the oxide-phase solid fraction varied linearly in this range, but research since that time has shown that the functional dependence is highly non-linear for multi-component oxide melts [15]. Since solid fraction has an important effect on viscosity which, in turn, strongly affects spreading behavior, this was one of the most important improvements to the code in the area of material properties evaluation.

Several other code improvements were also made. The capability to carry out inviscid and/or adiabatic spreading analysis was also added, so that analytical solutions as well as isothermal spreading tests could be calculated by appropriate selection of input data. The ability to model an interfacial heat transfer resistance at the melt-substrate interface was also added. This is important in terms of calculating spreading and solidification of metallic melts for which shrinkage at the melt-substrate interface can have a marked effect on the local heat transfer rate [14].

Thermo-physical properties affect spreading, and the most important of these is melt viscosity. The initial code version used the Ishii-Zuber [16] correlation to account for the effects of solids buildup in the melt on increasing corium viscosity. However, code applications to the database indicated that spreading behavior was better reproduced using the correlation developed by Ramacciotti et al. [17]. This model was added as a user option and was utilized in all calculations carried out as part of the code validation exercise. 
The code was validated against a total of 35 different cases that included analytical solutions, isothermal flow tests, and finally flow and freezing tests involving both simulant and reactor material tests. The validation calculations are documented in detail in [14].

\subsubsection{MELCOR}

The following MELCOR melt spreading model description has been condensed from [1]. The spreading model is formed by user-defined control functions in the input model. The melt spreading modeling is not built into the MELCOR code and may vary between different reactor model inputs.

In terms of cavity nodalization for spreading and core-concrete interaction analysis, the MELCOR CAV package divides the drywell floor area into three regions. The first region, which receives core debris exiting the reactor vessel, corresponds to the reactor pedestal floor and sump areas. Debris that accumulates in the pedestal can flow out through a doorway in the pedestal wall to a second region representing a 90 degree sector of the drywell floor. If the debris accumulates in this region to a sufficient depth, the material can spread further into the third region, which corresponds to the remaining 270 degree sector of the annular drywell which surrounds the reactor pedestal.

Two control systems are used to model debris relocation within the three cavity regions. The first represents bulk debris spillover from one region to another. The system monitors debris elevation and temperature within each region, both of which must satisfy user-defined threshold values for debris to move from one region into the next. In particular, when the debris is at or above the liquidus temperature of concrete, all material that exceeds a predefined elevation above the floor/debris surface in the adjoining cavity is relocated. When the debris in a cavity is at or below the solidus temperature of concrete, no flow is permitted. Between these two temperatures, restricted debris flow is permitted by increasing the required elevation difference in debris between the two cavities (i.e., more debris head is required to flow).

The second control system manages the debris spreading radius across the drywell floor from the pedestal to the drywell shell to approximate liner attack (note that this system is not implemented for molten core/concrete interaction rates). Debris entering the first two cavities is not immediately permitted to cover the entire surface area of the cavity floor. The maximum allowable debris spreading radius is defined as a function of time. If the debris temperature is at or above the liquidus temperature of the concrete, then the maximum transit velocity of the debris front to the cavity wall is calculated (i.e., results in 10 minutes to transverse the first cavity and 30 minutes to transverse the second cavity). When the debris temperature is at or below the concrete solidus, the debris front is assumed to be frozen, and lateral movement is precluded. A linear interpolation is performed to determine the debris front velocity at temperatures between these two values.

Full mixing of all debris into a single homogenous layer is assumed in each of these debris regions. The specific properties for concrete composition, ablation temperature, density, solidus temperature, and liquidus temperature are specified.

\subsection{COMPARISON OF MELT SPREADING RESULTS}

\subsubsection{Summary of Case Scenario and Modeling Assumptions}

The MELCOR pour scenario [1] is a low-pressure sequence in which the $1 \mathrm{~F} 1$ vessel is predicted to fail at 14.26 hours, leading to the gradual discharge of $\sim 141 \mathrm{t}$ of core debris into the drywell over the course of 67 minutes. Key input data for the spreading analysis deduced from MELCOR output are summarized in Table 1. MELCOR predicts the water depth in the drywell to be $\sim 55 \mathrm{~cm}$ at onset of the pour. The cumulative mass of relocated core debris as the sequence progresses is shown in Fig. 1 . The debris pour rate is highest right after the vessel fails, averaging $205 \mathrm{~kg} / \mathrm{sec}(\sim 28$ liters $/ \mathrm{sec})$ over the first 7 minutes of the transient. The balance of the material $(53 \mathrm{t})$ relocates over the following hour at varying rates, all of which are less than the initial rate. The debris temperature distribution in the lower head just 
before the vessel fails ranges from 1850 to $2100 \mathrm{~K}$. For the purposes of the MELTSPREAD analysis, an average core debris temperature of $1975 \mathrm{~K}$ was assumed [1]. The core melt composition (Table 1) consists primarily of core oxides $\left(\mathrm{UO}_{2}-\mathrm{ZrO}_{2}\right)$ with $\sim 43 \%$ of the cladding oxidized. The debris contains $\sim 20 \mathrm{wt} \%$ structural steel. Given the core debris temperature range predicted by MELCOR for this scenario, the metal phase is predicted to be fully liquid, while the oxide is predicted to be fully solid. The resultant average solids content in the debris at the time of vessel failure is thus estimated to be 56 vol\%. The melt is expected to be quite viscous with this amount of solids present. The decay heat level in the debris at the time of vessel failure (14.26 hours) is equivalent to $86 \mathrm{~W} / \mathrm{kg}$ fuel [1].

Table 1. Melt spreading input data from MELCOR $[1,8]$ accident analyses

\begin{tabular}{|c|c|}
\hline Case designator & MELCOR \\
\hline Sequence description & $\begin{array}{l}\text { Vessel failure at low } \\
\text { pressure }\end{array}$ \\
\hline Onset of Pour (hours) & 14.26 \\
\hline Pour Duration (sec) & 4030 \\
\hline Containment Pressure $(\mathrm{MPa})^{a}$ & 0.75 \\
\hline Water level on drywell floor at vessel failure $(\mathrm{cm})$ & 55 \\
\hline Melt Pour Temperature (K) & $\begin{array}{c}\text { Range: } 1850-2100 \\
\text { Average: } 1975\end{array}$ \\
\hline Oxide Phase Solidus-Liquidus Temp. $(\mathrm{K}-\mathrm{K})^{b}$ & $2215-2467$ \\
\hline Metal Phase Solidus-Liquidus Temp. $(\mathrm{K}-\mathrm{K})^{b}$ & $1705-1735$ \\
\hline Melt Solid Fraction at Temperature $(-)^{b}$ & 0.56 \\
\hline Decay Heat at Relocation (W/kg fuel) & 86 \\
\hline \multicolumn{2}{|l|}{ Total Pour Mass of Melt Constituent $(\mathrm{kg})$ : } \\
\hline $\mathrm{UO}_{2}$ & 69400 \\
\hline $\mathrm{Zr}$ & 25800 \\
\hline $\mathrm{ZrO}_{2}$ & 16600 \\
\hline $\mathrm{Cr}$ & 5900 \\
\hline $\mathrm{Cr}_{2} \mathrm{O}_{3}$ & 30 \\
\hline $\mathrm{Fe}$ & 20430 \\
\hline $\mathrm{FeO}$ & 230 \\
\hline $\mathrm{Ni}$ & 2530 \\
\hline $\mathrm{NiO}$ & 30 \\
\hline Total & 140950 \\
\hline
\end{tabular}

${ }^{a}$ Approximate; based on plant data.

${ }^{b}$ Calculated with CORQUENCH subroutines given composition and melt pour temperature. 


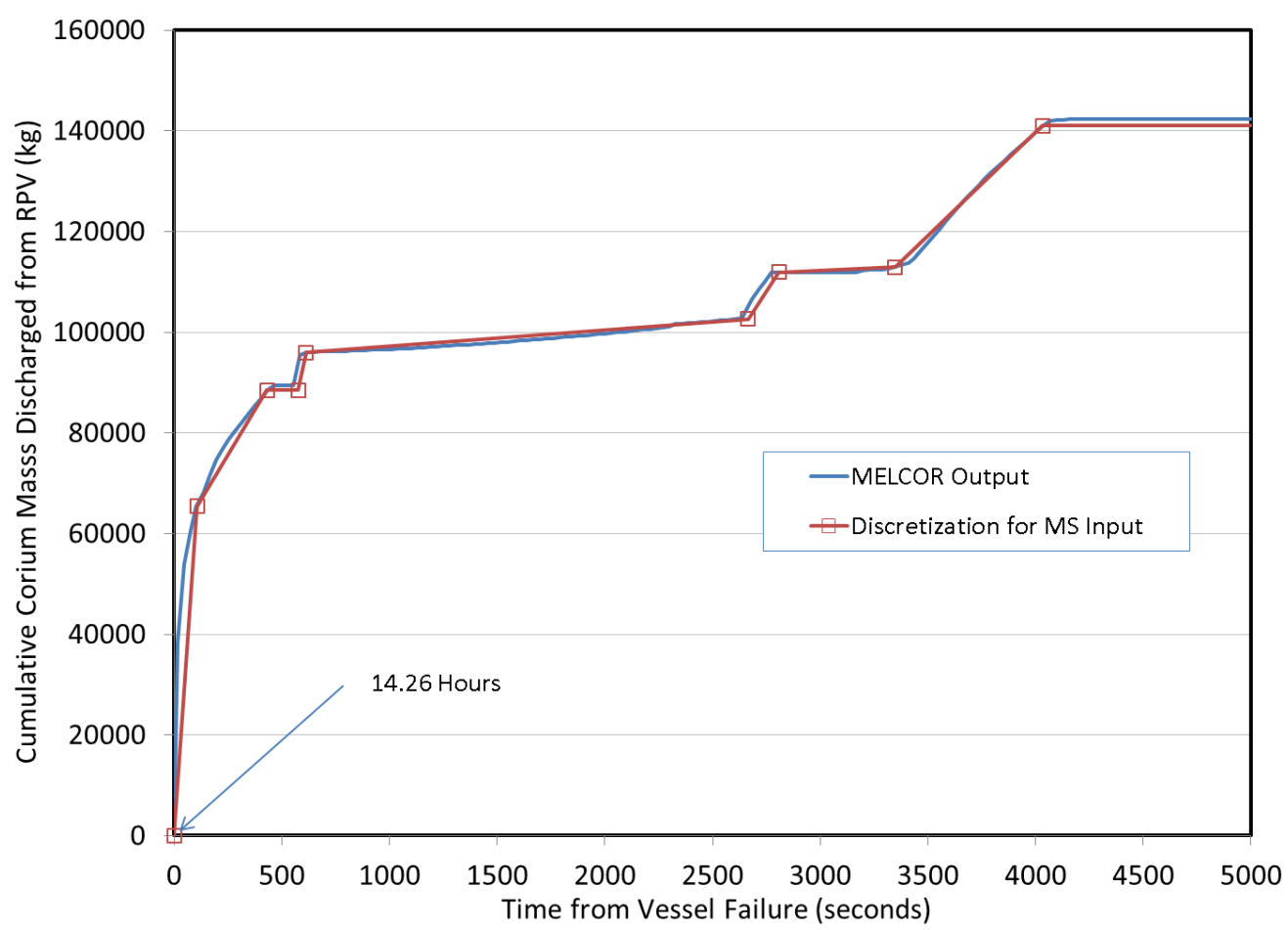

Fig. 1. Cumulative core debris discharge from RPV for MELCOR Sequence [1].

Containment dimensions and features for $1 \mathrm{~F} 1$ that are relevant for the spreading analysis are shown in Table 2. Due to the one-dimensional modeling limitations in MELTSPREAD, the two drywell sumps are combined into a single geometric entity that consists of a cylinder located at the pedestal centerline that is $2.23 \mathrm{~m}$ in diameter and $1.2 \mathrm{~m}$ deep. Thus, in the nodalization process the sump volume, total crosssectional area, and depth are conserved. Core material relocating from the reactor pressure vessel is assumed to drain directly into the sump region. The balance of the drywell floor from the sump edge to the pedestal inner wall is discretized into 13 uniform and cylindrical mesh cells. Flow through the pedestal doorway is assumed to occur in a one-dimensional channel; the $1.2 \mathrm{~m}$ flow distance is discretized into 12 nodes of equal size. Outside the pedestal doorway, the core melt is assumed to spread in a $90^{\circ}$ sector to the shell; this is the same spreading geometry assumed in the MELCOR analysis. The distance from the pedestal outer wall to the drywell shell is discretized into 28 nodes of equal size. After the melt contacts the liner, the flow is assumed to be diverted symmetrically into the two sides of the annulus. A coarser discretization was used in the annulus; that is, 28 nodes were used to model this area. Consistent with the MELCOR analysis, the composition of the $1 \mathrm{~F} 1$ drywell concrete was chosen to be the same as the default Basalt concrete composition that is embedded in MELCOR.

For the MELCOR spreading analysis, the 1F1 containment was assumed to be the same as Peach Bottom $[1,18]$. The relevant dimensions for this reactor are compared with $1 \mathrm{~F} 1$ in Table 2 . To examine the influence of the different cavity dimensions on the predicted spreading behavior, an additional MELTSPREAD case was run. The nodalization scheme was essentially the same as that used for $1 \mathrm{~F} 1$, with the mesh uniformly adjusted to account for the slightly different dimensions of Peach Bottom. Although the overall floor areas of the two containments are quite similar, the Peach Bottom pedestal area is $\sim 30 \%$ larger than $1 \mathrm{~F} 1$, and the sump volume is $\sim 20 \%$ larger. Finally, the Peach Bottom sump is much broader and shallower than $1 \mathrm{~F} 1$. This results in a significant difference (i.e., factor of $\sim 4$ ) in the ratio of sump sidewall-to-floor areas for the two units. 
Table 2. Comparison of 1F1 and Peach Bottom containment geometries

\begin{tabular}{|c|c|c|}
\hline Parameter & $\begin{array}{l}\text { 1F1 } \\
\text { PCV }\end{array}$ & $\begin{array}{c}\text { Peach Bottom } \\
\text { PCV }\end{array}$ \\
\hline Total sump cross-sectional area, $\mathrm{m}^{2}$ & 4.23 & 13.33 \\
\hline Sump depth, m & 1.20 & 0.445 \\
\hline Sump volume, $m^{3}$ & 5.07 & 5.93 \\
\hline Sump sidewall surface area-to-floor area ratio ${ }^{a}$ & 2.15 & 0.43 \\
\hline Pedestal inner radius, $\mathrm{m}$ & 2.50 & 3.09 \\
\hline Pedestal outer radius, $\mathrm{m}$ & 3.70 & 4.00 \\
\hline Shell radius (at contact with drywell floor), $\mathrm{m}$ & 6.55 & 6.62 \\
\hline Pedestal doorway width, $\mathrm{m}$ & 1.0 & 0.91 \\
\hline Shell radius (at contact with drywell floor), $\mathrm{m}$ & 6.55 & 6.62 \\
\hline Pedestal doorway width, $\mathrm{m}$ & 1.0 & 0.91 \\
\hline Pedestal floor area (includes sump cross-section), $m^{2}$ & 19.6 & 30.0 \\
\hline Drywell annulus floor area, $\mathrm{m}^{2}$ & 91.8 & 87.4 \\
\hline Total floor area, $\mathrm{m}^{2}$ & 111.4 & 117.4 \\
\hline
\end{tabular}

${ }^{a}$ Calculated on the basis of the cylindrical sump volume assumption made as part of these analyses.

General modeling assumptions used in the MELCOR spreading model were described previously (Section 2.1.2). Additional details regarding assumptions made as part of the MELCOR and MELTSPREAD spreading analyses are provided in [1] and [8], respectively.

\subsubsection{Melt Spreading Prediction Results}

In the previous MELTSPREAD-CORQUENCH study of ex-vessel behavior [8], a variety of parametric calculations were carried out examining the effects of melt pour rate, initial water depth on the cavity floor, and the potential for sump cover plate failure on spreading behavior. For the purposes of this study, the comparison is made here with the base case results in which the melt is discharged into the containment over a period of $\sim 67$ minutes (Table 1 and Fig. 1). The assumed pour temperature is in the range where the metal phase is expected to be entirely liquid, while the oxide would be solid. According to the MELTSPREAD viscosity subroutine, the viscosity of the core debris is $\sim 77 \mathrm{~Pa}$ sec at the assumed vessel exit temperature of $1975 \mathrm{~K}$, which is the same order of magnitude as chocolate syrup or ketchup. Thus, in this scenario the flow is expected to be dominated by viscous as well as freezing effects. Spreading is assumed to occur underwater with the water depth limited by the drywell vent line height of $\sim 60 \mathrm{~cm}$. Finally, the metal plates that cover the sump openings are assumed to fail at initial contact with the core debris, so that the sump must fill first before the material can spread beyond.

A comparison of floor spreading areas based on the MELTSPREAD and MELCOR modeling approaches is provided in Fig. 2. Two MELTSPREAD cases are shown; the first assumes spreading in the 1F1 drywell, while the second assumes spreading in Peach Bottom. This latter case is provided for direct comparison with the MELCOR results that utilized the Peach Bottom geometry [18]. Additional results are provided in Fig. 3, which shows the leading edge penetration for the two MELTSPREAD cases. Finally, Fig. 4 provides the MELTSPREAD predictions of melt depth adjacent to the drywell shell for these two cases.

\footnotetext{
${ }^{*}$ See, for example, http://en.wikipedia.org/wiki/Viscosity.
} 


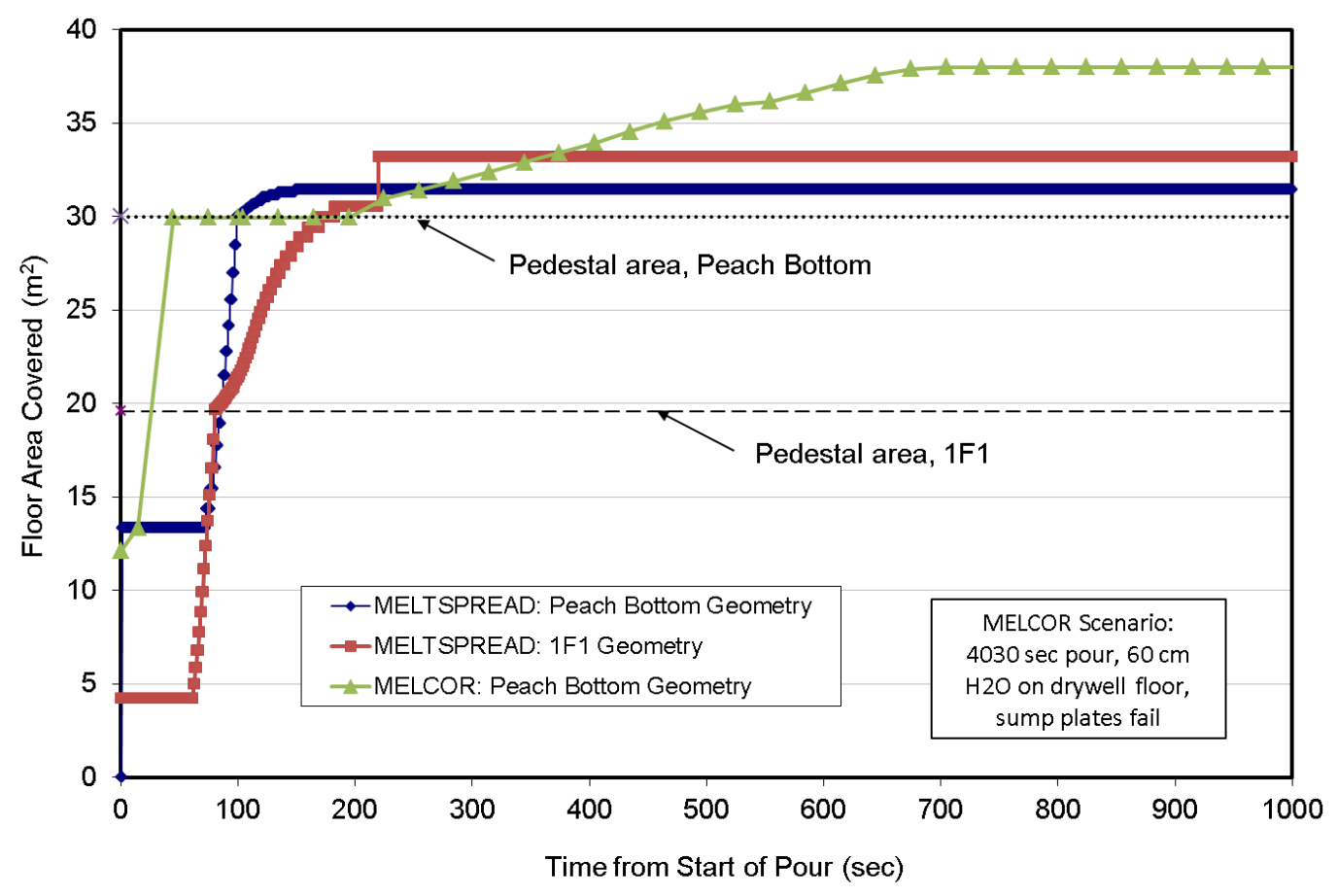

Fig. 2. Comparison of MELTSPREAD and MELCOR floor coverage predictions during spreading.

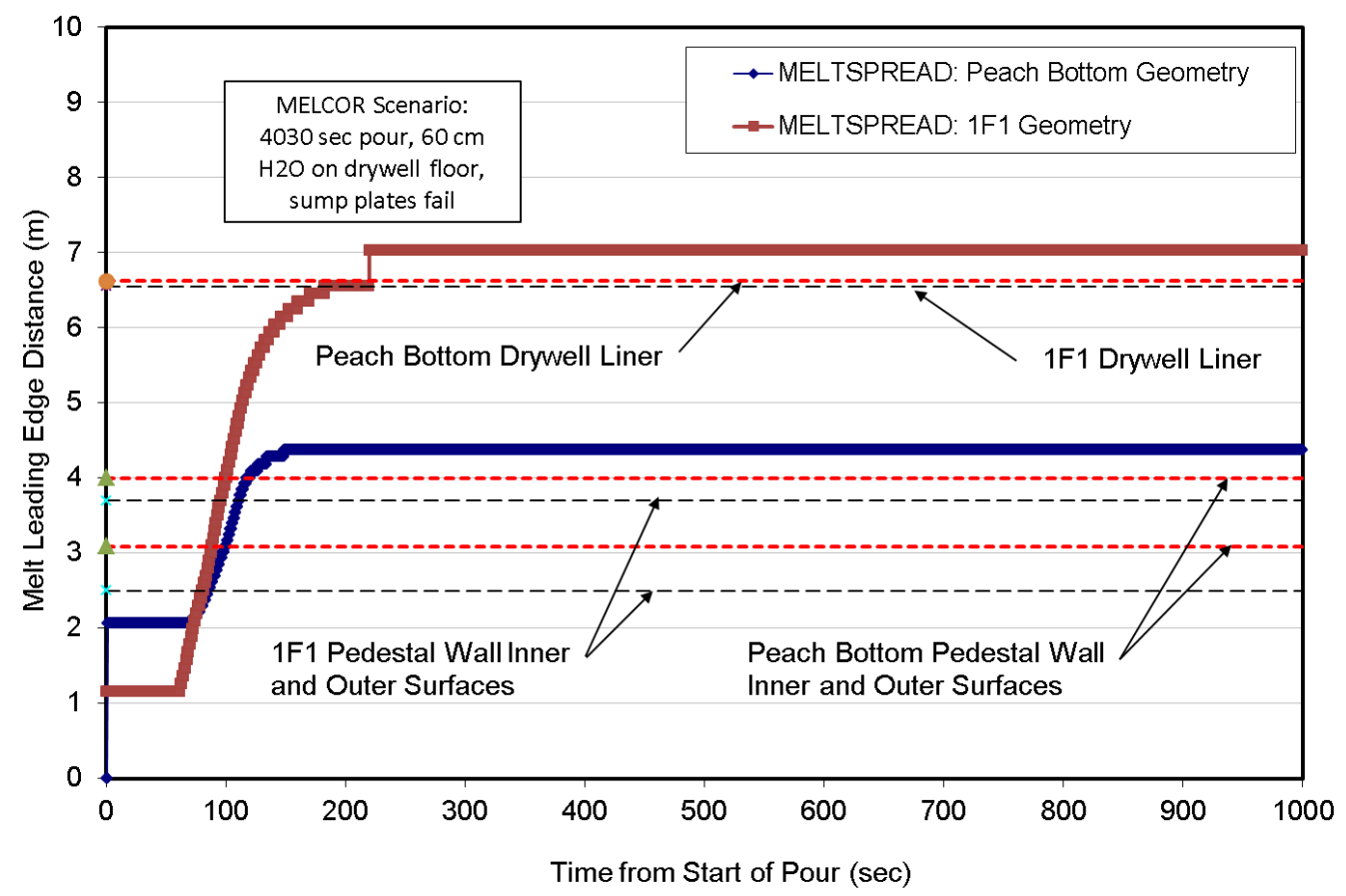

Fig. 3. MELTSPREAD predictions of leading edge penetration during spreading in the $1 F 1$ and Peach Bottom pedestal and drywell regions. 


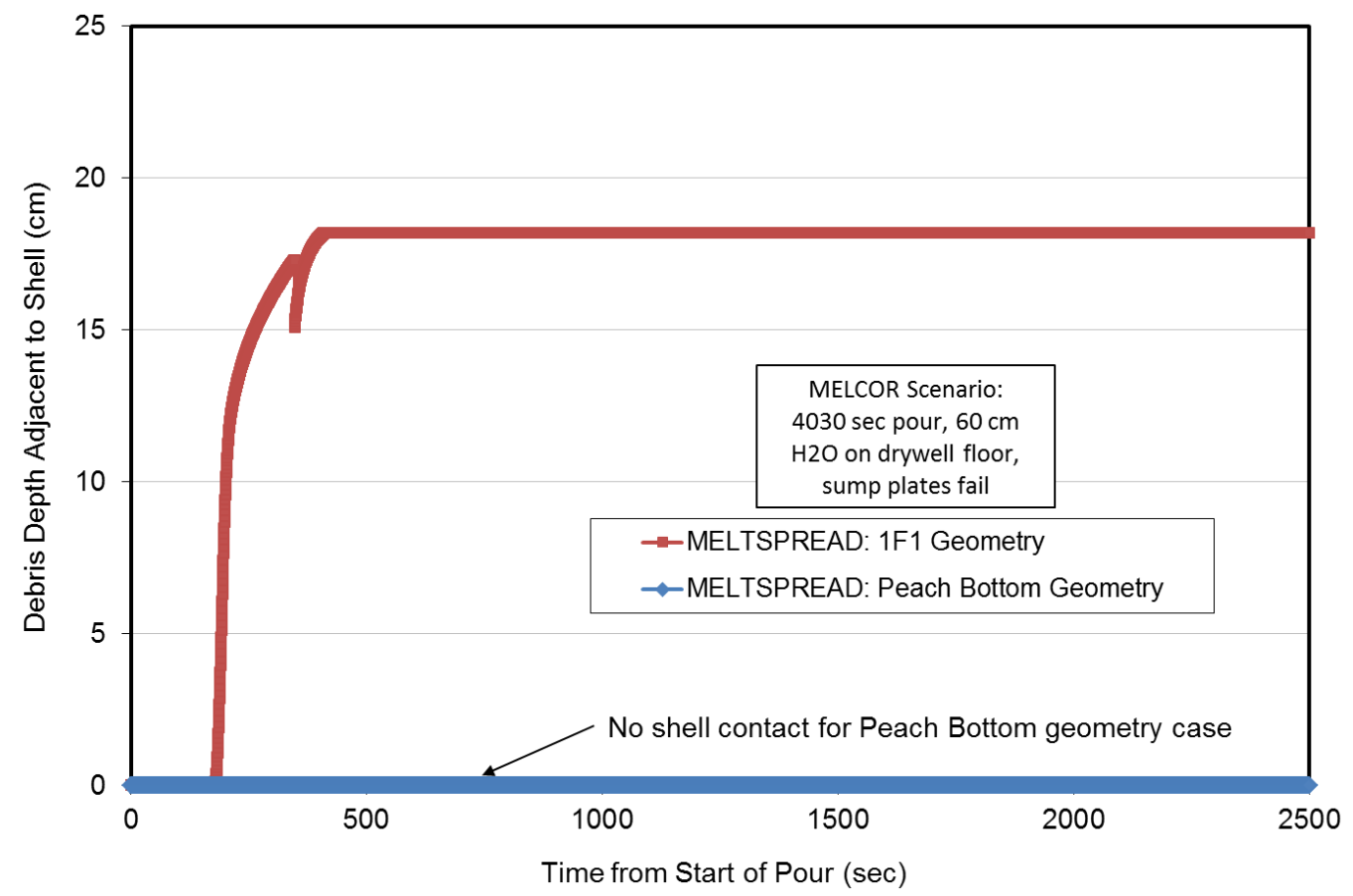

Fig. 4. MELTSPREAD predictions of melt depth adjacent to the drywell liner for the $1 F 1$ and Peach Bottom containment geometries.

Comparison of the two code cases in Fig. 2 for the Peach Bottom geometry allows the MELTSPREAD and MELCOR spreading models to be compared directly. MELCOR predicts melt accumulation and spreading out of the pedestal doorway at 194 seconds, whereas MELTSPREAD predicts earlier penetration into the drywell at 98 seconds. By the end of the spreading transient, MELCOR predicts $38 \mathrm{~m}^{2}$ of total floor area coverage, which is $21 \%$ more than MELTSPREAD (i.e., $31.4 \mathrm{~m}^{2}$ ). Although the area differences are not that large, they do reveal an important cavity geometry related effect; that is, in the Peach Bottom geometry, MELCOR predicts melt contact with the shell, while in the MELTPREAD analysis, melt solidification at the leading edge is predicted to stop the melt before contact with the shell (Fig. 3 and Fig. 4). Thus, this comparison indicates that containment geometry can influence spreading behavior and the ultimate course of the accident sequence, that is, failure of the drywell liner and containment bypass by thermal attack vs. other potential failure modes (e.g., drywell head lifting or main steam line failure).

As noted in Section 2.2.1, a relatively course mesh was used to discretize the drywell annulus past the $90^{\circ}$ sector outside the pedestal doorway. The apparent discontinuity in spreading area for the 1F1 case at 219 seconds is due to the fact that the melt spread to contact the shell, and the flow was subsequently diverted into the coarsely meshed annulus region. The discontinuity is thus reflective of the meshing characteristics and is not a numerical issue associated with the simulation. 


\section{LONG-TERM DEBRIS COOLABILITY COMPARISON}

The MELCOR code v1.8.3 through v2.1 models MCCI using the models and methodology from CORCON-Mod3. Minor modifications were made to integrate CORCON-Mod3 into MELCOR as noted in the MELCOR user and theory manuals [19]. The CORCON-Mod3 MCCI modeling methodology is described in detail in the user manual [12]. The CORQUENCH code, v3.03, is described in detail in the user manual [7], and key capabilities were summarized in [8].

Section 3.1 compares the MCCI modeling methodologies and options employed by CORQUENCH v3.03 and MELCOR v2.1 (CORCON-Mod3). Section 3.2 then compares the predictions from both codes under a variety of modeling options. This work builds upon previous work comparing the two codes [20, 21].

\subsection{COMPARISON OF LONG-TERM DEBRIS COOLABILITY MODELING}

This section summarizes the key differences and similarities between the CORQUENCH v3.03 and MELCOR v2.1 (CORCON-Mod3) codes with respect to the modeling methodologies employed and the modeling options available. As summarized in Table 3, there are a number of similarities and differences between phenomena accounted for in MELCOR and CORQUENCH. Some key modeling methodologies employed by the codes are discussed in Sections 3.1.1-3.1.12. The reader is referred to the code user manuals for complete explanation of the models $[7,12,19]$.

Table 3. Summary of MELCOR v2.1 (CORCON-Mod3) and CORQUENCH v3.03 phenomena

\begin{tabular}{|c|c|c|c|}
\hline \multicolumn{2}{|c|}{ Category } & MELCOR (CORCON-Mod3) & CORQUENCH \\
\hline \multicolumn{2}{|c|}{ Upward Heat Transfer } & $\begin{array}{l}\text { - Convection (if air present) } \\
\text { - Boiling curve (if water present) } \\
\text { - Thermal radiation }\end{array}$ & $\begin{array}{l}\text { - Convection (if air present) } \\
\text { - Boiling curve (if water present) } \\
\text { with early film breakdown option } \\
\text { - Thermal radiation } \\
\text { - Crust water ingression } \\
\text { - Melt eruptions } \\
\text { - Particle bed dryout }\end{array}$ \\
\hline \multicolumn{2}{|c|}{ Heat Generation } & $\begin{array}{l}\text { - Decay heat } \\
\text { - Chemical reactions }\end{array}$ & $\begin{array}{l}\text { - Decay heat } \\
\text { - Chemical reactions }\end{array}$ \\
\hline \multirow[t]{3}{*}{$\begin{array}{l}\text { Debris } \\
\text { Configuration }\end{array}$} & Top Surface & $\begin{array}{l}\text { - Liquid melt } \\
\text { - Crust }\end{array}$ & $\begin{array}{l}\text { - Liquid melt } \\
\text { - Crust } \\
\text { - Crust and particle bed } \\
\text { - Crust anchoring and failure }\end{array}$ \\
\hline & Melt & $\begin{array}{l}\text { - Homogeneous melt } \\
\text { - Melt layer segregation with multiple } \\
\text { (7) layers } \\
\text { - Swelled melt due to gas }\end{array}$ & $\begin{array}{l}\text { - Homogeneous melt } \\
\text { - Swelled melt due to gas }\end{array}$ \\
\hline & $\begin{array}{l}\text { Bottom and } \\
\text { Side Surface }\end{array}$ & - Allows for concrete surface crusts & $\begin{array}{l}\text { - Transient concrete ablation model } \\
\text { allows for concrete surface crusts }\end{array}$ \\
\hline
\end{tabular}


Table 3. Summary of MELCOR v2.1 (CORCON-Mod3) and CORQUENCH v3.03 phenomena (continued)

\begin{tabular}{|c|c|c|c|}
\hline \multicolumn{2}{|c|}{ Category } & MELCOR (CORCON-Mod3) & CORQUENCH \\
\hline \multirow[t]{3}{*}{$\begin{array}{l}\text { Concrete } \\
\text { Cavity }\end{array}$} & $\begin{array}{l}\text { Cavity } \\
\text { Geometry }\end{array}$ & $\begin{array}{l}\text { - Complex ablation cavity shape that is } \\
\text { 2-D axisymmetric }\end{array}$ & $\begin{array}{l}\text { - } 1-\mathrm{D} \text { axial } \\
\text { - 2-D axisymmetric cylinder } \\
\text { - 2-D rectilinear notch geom. }\end{array}$ \\
\hline & Ablation & - Quasi-steady & $\begin{array}{l}\text { - Quasi-steady } \\
\text { - Fully developed concrete dryout } \\
\text { - Transient concrete dryout }\end{array}$ \\
\hline & Composition & $\begin{array}{l}\text { - Preset or user-defined composition } \\
\text { - One layer }\end{array}$ & $\begin{array}{l}\text { - Preset or user-defined composition } \\
\text { - One or multiple layers }\end{array}$ \\
\hline \multirow{3}{*}{$\begin{array}{l}\text { Debris } \\
\text { Material } \\
\text { Properties }\end{array}$} & Viscosity & - Enhancement due to solids & - Enhancement due to solids \\
\hline & $\begin{array}{l}\text { Thermal } \\
\text { Conductivity }\end{array}$ & $\begin{array}{l}\text { Molar fraction weighting, } \\
\text { temperature independent }\end{array}$ & $\begin{array}{l}\text { - Volume fraction weighting, } \\
\text { temperature dependent }\end{array}$ \\
\hline & Emissivity & - User specified & - Volumetric weighting of phases \\
\hline
\end{tabular}

\subsubsection{Water Ingression}

As the upper crust on the melt pool cools, cracks can form allowing water to ingress. Water ingression into the crust serves to augment upward heat transfer and facilitates the formation of a thicker crust. In contrast, if the crust is impervious to water, the maximum top crust thickness is limited by conduction and is of the order of $10 \mathrm{~cm}$. As part of the SSWICS test series within the MCCI-1 and MCCI-2 programs, water ingression into the top crust was investigated [22]. The SSWICS test data on water ingression is supported by the COTELS, MACE, and CCI test series [13] performed as part of the MCCI-1 and MCCI-2 programs. The tests demonstrated that the crust is permeable to water ingression and have provided data for model validation.

MELCOR v2.1 assumes the crust is impervious. CORQUENCH includes an impervious crust modeling option as well as a water ingression modeling option to account for the enhanced coolability of the crust. Water ingression is modeled to occur once the total upward heat transfer from the crust falls below the dryout limit. Two options exist for determining the dryout limit. One option allows a userspecified crust permeability to be specified, and the corresponding crust dryout limit is then evaluated with the Jones et al. [23] model. The second option is to use a model based on the work performed during the OECD/MCCI program [24, 25]. This water ingression model incorporated into CORQUENCH has been validated based on the data from the aforementioned MCCI tests.

\subsubsection{Melt Eruptions}

Melt eruptions refer to a phenomenon wherein gas evolved from concrete decomposition entrains melt from the melt pool up through channels in the top crust. The entrained melt quenches and forms a particle bed on top the crust. Melt eruptions increase the upward heat transfer and have been shown theoretically and experimentally to have a large potential to augment melt coolability. Cooling of the particle bed, which forms on top of the crust, must be considered when determining the upward heat transfer.

MELCOR v2.1 does not allow for melt eruptions. CORQUENCH v3.03 contains three modeling options for this cooling mechanism. The first is simply to specify an entrainment coefficient. The amount of melt ejected by melt eruptions is then determined by the product of the melt entrainment coefficient and the superficial gas velocity of the concrete decomposition gases passing through the melt. The second determines the entrainment coefficient based on the Ricou-Spalding correlation [26], which contains an 
empirical constant. A suggested value for the empirical constant has been developed based on post-test examination of past MCCI tests [7]. The last option is a mechanistic model developed by Farmer [27] that determines the number of eruption sites, hole diameter, and amount of melt being ejected. Finally, there is ongoing work to add additional melt eruption models, based on the work of Tourniaire et al. [28] and Robb et al. [29], to CORQUENCH. After the melt is ejected, CORQUENCH quenches the material and adds it to a particle bed, of user-defined porosity and particle size, which is located on top of the upper crust. The upward heat transfer models also take into account the presence of this particle bed.

\subsubsection{Boiling Curve}

While a top crust is absent and water is on top of the melt, film boiling occurs. The film boiling is augmented by barbotage of gas passing through the melt pool. After a top crust forms, the upward boiling heat transfer can vary from film boiling, through transition, and finally enter the nucleate boiling regime.

A full boiling curve is implemented into both MELCOR and CORQUENCH. Both codes use the Rohsenow correlation [30] for nucleate boiling and the Ivey-Morris [31] modifications of the Zuber correlation [32] for the critical heat flux. Both codes include the heat transfer enhancement during film boiling due to gas barbotage with CORQUENCH using a more rigorous approach.

During separate effect and reactor materials tests, film boiling has been observed to break down early and transition to the nucleate boiling regime. CORQUENCH includes the option to force early film boiling breakdown through a user-specified criterion.

Due to the lack of a water ingression model, MELCOR allows the user to parametrically scale the boiling curve through the use of a multiplier. Current MELCOR best practice is to use a $10.0 \times$ multiplier $[19,33]$.

\subsubsection{Crust Composition and Thermal Conductivity}

All crusts (top, sidewalls, and bottom) are modeled in MELCOR as having the same composition as the melt pool. In CORQUENCH, the composition of the top, sidewall, and bottom crusts as well as the melt pool (and particle bed formed by melt eruptions) are tracked independently. Tracking the differences in composition is important as early crust formation can have higher metals contents and may have a higher melting temperature as more concrete constituents are added to the melt pool.

MELCOR determines the thermal conductivity of a mixture through mole-fraction averaging of the species temperature-independent thermal conductivities. CORQUENCH determines a thermal conductivity for the oxide phase and the metal phase based on volumetric averaging. The combined oxide-metal mixture thermal conductivity is then determined using the correlation of Lichteneker [34], which is also based on volumetric fractions.

To help correct the issue of using a single temperature-independent thermal conductivity for each species, CORCON-Mod3 has a user-defined multiplier for the metal phase thermal conductivity. Besides the issue of the temperature-independent thermal conductivities, without a water ingression model, MELCOR is limited to forming a conduction-limited thickness of crust (a function of heat generation rate and crust thermal conductivity). Depending on the crust surface temperature, crust thermal conductivity, and the decay power in the crust, the conduction-limited crust thickness is on the order of $10 \mathrm{~cm}$. Said differently, melt pools much deeper than $10 \mathrm{~cm}$ will not be predicted to solidify. To help accommodate both of these issues, MELCOR contains a user-defined multiplier for the oxide and metallic phase thermal conductivity. Current MELCOR "best practice" is to increase both the oxide and metal thermal conductivity by $5.0 \times[19,33]$. 


\subsubsection{Melt Viscosity}

There are a number of differences in how each code determines the melt viscosity. The reader is referred to the code manuals $[7,12]$ and references for a full description of the formulas employed in determining the melt viscosity.

In both codes the oxidic-phase viscosity is determined in two different methods depending on the $\mathrm{SiO}_{2}$ content of the melt. For low $\mathrm{SiO}_{2}$ content melts, MELCOR determines the oxidic-phase viscosity using the Kendall-Monroe formula [35] (mole fraction weighting) while CORQUENCH uses the Andrade formula as described by Nazare et al. [36] (combination of molar weighting and molar volume weighting). For high $\mathrm{SiO}_{2}$ content melts, the oxidic-phase viscosity is determined using the model developed by Shaw [37].

The metallic phase viscosity is determined in CORQUENCH in the same manner as the oxidic phase, whereas it is assumed to equal that of iron in MELCOR.

Both codes include the viscosity enhancement effects of solids within the melt. The solid fraction in MELCOR is modeled as varying linearly between the pool mixture solidus and liquidus temperatures. The metallic-phase solid fraction in CORQUENCH is determined by assuming it varies linearly between the metallic-phase solidus and liquidus temperatures. The oxide solid fraction in CORQUENCH is determined through two different user options, either based on a phase diagram or it is assumed to vary linearly between the oxide-phase solidus and liquidus. The combined solid fraction in the melt pool is then determined through volume fraction weighting of each phase's solid fraction.

The melt pool viscosity, taking into account the oxidic and metallic phases as well as solids, is then determined using the Kunitz correlation [38] in both codes. CORQUENCH also has the option to determine the viscosity using the method proposed by Ishii and Zuber [39].

\subsubsection{Melt Emissivity}

The emissivity of the melt is specified by the user in MELCOR. The default is 0.6 for the melt oxidic and metallic phase as well as the surroundings [19]. To augment melt coolability, the value suggested for best modeling practices is 0.9 for the melt oxidic and metallic phase and surroundings $[19,33]$. In CORQUENCH the melt pool emissivity is determined by volumetric weighting of predefined values for the oxidic (0.83) and metallic (0.30) phases. The emissivity of the surroundings is currently user specified.

\subsubsection{Crust Anchoring}

During MCCI the crust may anchor to the sidewalls of an experimental test section or the walls of the reactor cavity. If the crust is able to support itself, the underlying melt could separate from the crust, forming a gas layer between the melt and top crust. This has been shown to greatly impact melt coolability in laboratory-scale MCCI tests [40]. However, at plant scale the crust strength is likely not sufficient to support itself and the crust will likely remain floating on top of the melt. The MACE, MCCI-1, and MCCI-2 experimental programs have provided much crust strength information [40].

MELCOR does not contain a model to account for this phenomenon. CORQUENCH contains a model that determines if crust bridging occurs based on simple material mechanics relations given a userspecified crust strength.

\subsubsection{Concrete Ablation and Interstitial Crust Formation}

MELCOR and CORQUENCH both contain a quasi-steady concrete ablation model for which all the energy deposited into the concrete goes directly into concrete ablation. However, during the early stages of melt-concrete contact, a transient heat-up of the cool concrete occurs. To account for this, CORQUENCH also contains two other more rigorous ablation models. For the first model, 
CORQUENCH tracks the thermal boundary layer propagation in the concrete. In this model, the code is initialized with a fully developed temperature profile in the concrete. Temperature and spatial dependent degradation of the concrete, and subsequent release of water and carbon dioxide, are determined based on the propagating temperature profile. For the second model, CORQUENCH captures the initial heat-up transient of the concrete by containing a fully transient concrete heat-up and ablation model.

Both codes include the capability to model the formation of interstitial crusts between the melt and concrete interface. If the melt surface temperature drops below the melt solidification temperature, a crust forms and can grow. The crust formation model is only available in CORQUENCH when used in conjunction with the transient concrete heat-up and ablation model.

As noted in Section 3.1.4, the interstitial crust composition is assumed to be the same as the melt composition in MELCOR, whereas CORQUENCH tracks the various (top, side, bottom) crust compositions separately.

\subsubsection{Melt Pool Configuration and Void Fraction}

MELCOR has the ability to model multiple segregated layers of melt and determine whether they mix or stratify. CORQUENCH models the melt as homogeneous.

The pool swells as concrete decomposition gases pass through the melt pool. The height of the melt pool affects the radial melt-concrete interface area and therefore the radial heat transfer and ablation. MELCOR determines the pool swell by using a correlation by Brockmann [41]. CORQUENCH contains Brockmann's correlation as wells as options to use a correlation by Wallis [42] or Kataoka and Ishii [43].

\subsubsection{Computational Geometry}

MELCOR has an advanced cavity shape tracking model. CORQUENCH maintains a simple (1-D axial, 2-D cylindrical, or 2-D rectilinear notch) cavity geometry.

With respect to axial ablation, MELCOR's cavity tracking model adds little benefit over the simple axial tracking used by CORQUENCH. However, the cavity tracking model in MELCOR allows for much more detailed radial ablation tracking. This also allows for the radial heat transfer to depend on the surface inclination in MELCOR. MELCOR's cavity tracking model allows for the resolution of different concrete ablation rates for different segregated melt layers, if present.

\subsubsection{Chemical Reactions}

MELCOR and CORQUENCH account for a number of chemical reactions within the melt pool between melt constituents and the concrete decomposition gases. MELCOR includes a more rigorous treatment of the potential reactions than that of CORQUENCH.

CORQUENCH selectively oxidizes metals in a hierarchy with zirconium being oxidized first followed by chromium and then iron. MELCOR assumes chemical equilibrium is achieved among 56 chemical species and 15 elements each time step. Chemical equilibrium is determined through minimizing the Gibbs free energy of the mixture. Both codes include the ability to model condensedphase reactions between $\mathrm{Zr}$ and $\mathrm{SiO}_{2}$ which proceeds in parallel to the other reactions. Including this reaction was found to be necessary based on the SURC-4 test and is important for high-silica, low-gas concretes [12]. Unique to CORQUENCH is the condensed-phase reaction between $\mathrm{Zr}$ and $\mathrm{SiO}_{2}$ that leads to the formation of $\mathrm{SiO}(\mathrm{g})$ when the melt pool temperature is above $2784 \mathrm{~K}$.

Neither code accounts for melt pool reactions with the above atmosphere (CORCON-Mod3 contains a model for atmosphere surface reactions, but it is described as being disabled [12]).

Finally, it should be noted MELCOR does not accommodate $\mathrm{B}_{4} \mathrm{C}$ in the melt, a key core constituent in boiling water reactors. 


\subsubsection{Phase Diagram - Oxidic- and Metallic-Phase Solidus and Liquidus Temperatures}

Both CORQUENCH and MELCOR determine separate solidus and liquidus temperatures for the metallic and oxidic phases. The following is only a brief summary of the methodologies employed, and the reader is referred to the manuals for complete descriptions $[7,12,19]$.

For the oxidic phase, CORCON-Mod3 contained two options for determining the solidus and liquidus temperatures. One option assumes an ideal solution for the solid phase, while the other assumes eutectic interactions occur. After CORCON-Mod3's integration into MELCOR, only the ideal solution methodology is available to the user. The oxidic phase is divided into two components, one for the fuel oxides and the concrete and steel oxides form the other. The fuel oxide component solidus and liquidus temperatures are determined through a relation for the $\mathrm{UO}_{2}-\mathrm{ZrO}_{2}$ system. The concrete and steel oxide component solidus and liquidus temperatures are based on weighting of an internal library of property data for each constituent. The solidus and liquidus temperatures of the oxidic phase are then determined through weighting the two components using a relation described in the CORCON-Mod3 manual [12]. Note that it has been experimentally shown that the mixture does not behave as an ideal solution and that eutectic interactions occur with the addition of concrete oxides. The addition of concrete oxides have a non-linear impact on the melt solidus temperature, resulting in a mixture solidus temperature approaching that of concrete for melt concrete oxide fractions near $15 \mathrm{wt} \%$.

For the CORQUENCH oxidic phase, the methodology determines the oxide liquidus and solidus temperature through a series of three steps, each taking into account increased complexity of the influence of additional constituents. First the solidus and liquidus temperatures are determined assuming fully oxidized fuel-cladding conditions based on the Lamberston-Mueller phase diagram [44]. Next, the corecladding-concrete liquidus and solidus temperatures are determined using extrapolated data obtained by Roche et al [45]. Finally, the solidus and liquidus temperatures are determined for partially oxidized fuel and cladding using a pseudo-binary phase diagram based on the compilation of work of Chevalier et al [46], Lamberston-Mueller [44], and Farmer and Spencer [47].

For the metallic phase, MELCOR determines the phase diagram based on a simple fit of the Cr-Fe-Ni ternary-phase diagram. The presence of other metallic constituents, which may depress the melting point, is ignored. In CORQUENCH, if the metallic phase consists of stainless steel constituents, then the solidus and liquidus temperatures are determined based on a Fe-Cr-Ni ternary-phase diagram. If other metals are present, the solidus and liquidus temperatures are determined through molar weighting of the metallic constituents' melting points. CORQUENCH has the user option to either include the zirconium in solution with the metallic phase or as a eutectic with the oxide phase.

\subsection{COMPARISON OF LONG-TERM DEBRIS COOLABILITY PREDICTIONS}

For the current study, MCCI predictions from MELCOR and CORQUENCH are compared against one another for the core melt conditions predicted for the Fukushima Daiichi Unit 1 sump. The codes are also exercised under a range of modeling assumptions, and their predictions were compared.

The models employed for the simulation comparisons are summarized in Section 3.2.1. The scenario setup, such as the concrete composition, cavity geometry, and melt pour conditions, is summarized in Section 3.2.2. Finally, comparisons are presented in Section 3.2.3 for the case where the codes use similar modeling options and Section 3.2.4 for code best-estimate predictions.

\subsubsection{Simulation Modeling Options}

Two different cases were run for each code. First, models and parameters were selected in MELCOR and CORQUENCH such that they used similar modeling methodologies and models. This enables a comparison between codes under similar modeling assumptions. These two simulation cases under similar modeling options are labeled CORQUENCH-S and MELCOR-S. Second, "best practice" models and modeling parameter values were used in both codes. This enables the comparison of best-estimate 
predictions by both codes. These two best-estimate simulation cases are labeled CORQUENCH-B and MELCOR-B. The modeling options employed for the various cases are summarized in Table 4 and described in more detail below.

Table 4. Summary of modeling options and parameters for coolability simulations

\begin{tabular}{|l|c|c|c|c|}
\hline \multirow{2}{*}{ Parameter/phenom. } & \multicolumn{4}{|c|}{ Modeling case } \\
\cline { 2 - 5 } & CORQUENCH-S & MELCOR-S & CORQUENCH-B & MELCOR-B \\
\hline Water Ingression & Disabled & NA & Lister-Epstien & NA \\
\hline Melt Eruptions & Disabled & NA & Farmer model & NA \\
\hline Crust Anchoring & Disabled & NA & Disabled $^{a}$ & NA \\
\hline Void Fraction & Brockmann & Brockmann & Brockmann & Brockmann \\
\hline Melt Solids Fraction & $\begin{array}{c}\text { Linear Interp. Oxide } \\
\text { Sol. \& Liq. Temp. }\end{array}$ & $\begin{array}{c}\text { Linear Interp. Melt } \\
\text { Sol. \& Liq. Temp. }\end{array}$ & Phase diagram & $\begin{array}{l}\text { Linear Interp. Melt } \\
\text { Sol. \& Liq. Temp. }\end{array}$ \\
\hline $\begin{array}{l}\text { Solids impact on } \\
\text { Viscosity }\end{array}$ & Kunitz & Kunitz & Ishii-Zuber & Kunitz \\
\hline $\begin{array}{l}\text { Melt and Crust } \\
\text { Thermal Conductivity }\end{array}$ & Model & $1 \mathrm{x}$ & Model & $5 \mathrm{x}$ \\
\hline Boiling Curve & Model & $1 \mathrm{x}$ & Model & $10 \mathrm{x}$ \\
\hline Early Film Breakdown & Disabled & NA & 0.5 & NA \\
\hline Melt Pool Config & Homogeneous & Homogeneous & Homogeneous & Homogeneous \\
\hline Zr-SiO2 reaction & Enabled & Enabled & Enabled & Enabled \\
\hline Ablation model & $\begin{array}{c}\text { Quasi-steady } \\
\text { Slag Film }\end{array}$ & Quasi-steady & $\begin{array}{c}\text { Transient } \\
\text { Slab Film }\end{array}$ & Quasi-steady \\
Slag Film
\end{tabular}

${ }^{a}$ Assumed not to occur at this scale based on findings from the MACE-M3b test [48].

\section{CORQUENCH-S and MELCOR-S: "Similar Modeling” Case Setup}

In both codes, the pool void fraction is determined based on the model by Brockmann. The amount of solids in the melt is determined by linear interpolation between the oxide solidus and liquids temperature in CORQUENCH and the melt solidus and liquidus temperature in MELCOR. The increase in viscosity due to solids is based on the model by Kunitz for both codes. Crust anchoring, water ingression, melt eruption models have been disabled in CORQUENCH as these are not available in MELCOR. The quasisteady concrete ablation model is used as this is the only option available in MELCOR. Early film boiling breakdown was disabled in CORQUENCH as this modeling option is not available in MELCOR. Both codes use their internal boiling curve without any modifications or enhancements. Both codes use the slag film model of Bradley in determining the heat transfer to the vertical and horizontal concrete surfaces. In MELCOR, the melt pool is forced to be homogeneous as this is the only melt pool configuration available in CORQUENCH. In MELCOR the melt emissivity is specified to be 0.7 in order to be similar to the value determined by CORQUENCH. Both codes used internal routines to determine the melt and crusts' thermal conductivities. 


\section{CORQUENCH-B: "Best Practice” Case Setup}

In general, the CORQUENCH modeling options were selected to match those recommended in the user manual. Specifically, water ingression was enabled, using the modified Lister-Epstein model, with a value for the user-defined empirical coefficient of 9.0. Melt eruptions were modeled using the Argonne National Laboratory (ANL) mechanistic model. The transient concrete ablation model was selected with the ability for interstitial melt-concrete crusts to form. The crusts were assumed to be permeable to the slag generated by the decomposing concrete and are assumed to fail when the thickness falls below the mechanical stability limit under the applied hydrostatic load of the melt. The slag film model of Bradley was used to determine the heat transfer to the vertical and horizontal concrete surfaces. The early film boiling breakdown was specified to occur once it reached $0.5 \times$ the predicted value for critical heat flux. Condensed-phase reactions between zirconium and $\mathrm{SiO}_{2}$ were calculated. The effect of solids buildup on the melt viscosity was determined using the Ishii-Zuber model. The solids fraction in the melt was determined based on the phase diagram for siliceous-type (SIL) concrete. The pool void fraction is determined based on the model by Brockmann. The crust anchoring model for the top crust was disabled. At this scale, based on the MACE M3b test results, an anchored crust would likely fail [48].

\section{MELCOR-B: "Best Practice" Case Setup}

Without water ingression into the top crust of the melt, the crust thickness is limited to thicknesses on the order of $10 \mathrm{~cm}$. Therefore, melt pools deeper than approximately $10 \mathrm{~cm}$ are generally not predicted to cool without water ingression. The melt eruption phenomenon also increases coolability by transforming the melt pool into a particulate debris bed, a coolable geometry. As noted previously, these phenomena have been observed experimentally.

To offset this modeling deficiency, three parameters are parametrically varied in MELCOR to increase upward heat transfer and melt pool coolability. These parameters have been modified to match those recommended in the user manual [19] and also proposed in the pre-decisional "best modeling practices" report [33]. The boiling heat transfer rate from the top surface of the melt to the overlying water is increased by a factor of 10 . The melt and crust thermal conductivity, of both the oxide and metallic phases (or homogenous phase), are increased by a factor of 5 . This enables the formation of a conduction-limited crust of approximately $50 \mathrm{~cm}$ as opposed to $10 \mathrm{~cm}$. Finally, the emissivity of the melt and surroundings is increased to 0.9 .

\subsubsection{Simulation Scenario Setup}

A simple cylindrical cavity was modeled in both MELCOR and CORQUENCH. This facilitates a comparison between modeling tools which limits the influence of geometric modeling differences between codes. The cylinder has a floor area of $2.1025 \mathrm{~m}^{2}(0.818 \mathrm{~m}$ radius $)$, which is the same floor area as one of the sumps in 1F1. The exact composition of the concrete at Fukushima Daiichi Unit 1 is not known to the authors; however, it is of the basaltic-type.The concrete composition used in the simulations is that specified in Table 5 [12]. The initial conditions for the simulations are provided in Table 6 . These were taken from [8] for the "MELCOR-1-5" scenario for the sump region. This scenario was based on melt pour timing and conditions predicted by MELCOR [1]. For the long-term coolability analyses, the starting time is assumed to be 15.4 hours after reactor shutdown, at which time the melt had finished spreading and containment was already flooded, the initial melt temperature was taken as $2110 \mathrm{~K}$, and containment pressure was $0.75 \mathrm{MPa}$. The simulations were run for up to 2 days of simulated time. After 2 days of MCCI, the initial chemical reactions have all occurred or the melt has quenched. The assumed decay heat is given by Table 7 . 
Table 5. Basaltic concrete composition assumed in analyses (CORCON Mod3 basalt [12])

\begin{tabular}{|c|c|}
\hline Constituent & wt\% \\
\hline $\mathrm{SiO}_{2}$ & 54.84 \\
\hline $\mathrm{CaO}$ & 8.82 \\
\hline $\mathrm{Al}_{2} \mathrm{O}_{3}$ & 8.32 \\
\hline $\mathrm{K}_{2} \mathrm{O}$ & 5.39 \\
\hline $\mathrm{Fe}_{2} \mathrm{O}_{3}$ & 6.26 \\
\hline $\mathrm{TiO}_{2}$ & 1.05 \\
\hline $\mathrm{MgO}$ & 6.16 \\
\hline $\mathrm{Na}_{2} \mathrm{O}$ & 1.8 \\
\hline $\mathrm{H}_{2} \mathrm{O}$ & 5.86 \\
\hline $\mathrm{CO}_{2}$ & 1.5 \\
\hline
\end{tabular}

Table 6. Initial melt conditions

\begin{tabular}{|l|c|}
\hline \multicolumn{1}{|c|}{ Case designator } & MELCOR \\
\hline Sequence description & $\begin{array}{c}\text { Vessel failure at low } \\
\text { RPV pressure }\end{array}$ \\
\hline Simulation start time (h after SCRAM) & 15.42 \\
\hline Containment pressure $(\mathrm{MPa})$ & 0.75 \\
\hline Water level on drywell floor at vessel failure $(\mathrm{cm})$ & 55 \\
\hline Initial melt temperature $(\mathrm{K})$ & 2110 \\
\hline Sump area $\left(\mathrm{m}^{2}\right)$ & 2.1025 \\
\hline Total pour mass of melt constituent $(\mathrm{kg}):$ & 14089.2 \\
\hline $\mathrm{UO}{ }_{2}$ & 5269.6 \\
\hline $\mathrm{Zr}$ & 3370.0 \\
\hline $\mathrm{ZrO}$ & 1205.1 \\
\hline $\mathrm{Cr}_{2}$ & 6.1 \\
\hline $\mathrm{Cr}_{2} \mathrm{O}_{3}$ & 4172.8 \\
\hline $\mathrm{Fe}$ & 46.7 \\
\hline $\mathrm{FeO}$ & 516.8 \\
\hline $\mathrm{Ni}$ & 6.1 \\
\hline $\mathrm{NiO}$ & 0 \\
\hline $\mathrm{B}_{4} \mathrm{C}$ & 28682.4 \\
\hline $\mathrm{Total}^{a}$ & \\
\hline
\end{tabular}

${ }^{a}$ MELCOR does not accommodate $\mathrm{B}_{4} \mathrm{C}$. 
Table 7. Assumed decay heat

\begin{tabular}{|c|c|c|c|c|}
\hline & $\begin{array}{l}\text { Time since } \\
\text { SCRAM }\end{array}$ & $\begin{array}{c}\text { Simulation } \\
\text { time }\end{array}$ & $\begin{array}{c}\text { Relative power } \\
(\text { P/Po) }\end{array}$ & $\begin{array}{l}\text { Specific } \\
\text { power }^{a}\end{array}$ \\
\hline & [min] & [min] & {$[-]$} & {$\left[\mathrm{W} / \mathrm{kg} \mathrm{UO}_{2}\right]$} \\
\hline 1 & 925.3 & 0.00 & 0.004495 & 79.52 \\
\hline 2 & 960 & 34.7 & 0.004447 & 78.68 \\
\hline 3 & 1080 & 154.7 & 0.004307 & 76.20 \\
\hline 4 & 1200 & 274.7 & 0.004183 & 74.01 \\
\hline 5 & 1440 & 514.7 & 0.003979 & 70.40 \\
\hline 6 & 1800 & 874.7 & 0.003709 & 65.63 \\
\hline 7 & 2160 & 1234.7 & 0.003453 & 61.10 \\
\hline 8 & 2520 & 1594.7 & 0.003251 & 57.51 \\
\hline 9 & 2880 & 1954.7 & 0.003084 & 54.57 \\
\hline 10 & 3600 & 2674.7 & 0.002826 & 50.00 \\
\hline 11 & 4320 & 3394.7 & 0.002631 & 46.55 \\
\hline 12 & 5040 & 4114.7 & 0.002476 & 43.81 \\
\hline 13 & 5760 & 4834.7 & 0.002350 & 41.57 \\
\hline 14 & 7200 & 6274.7 & 0.002153 & 38.09 \\
\hline 15 & 8640 & 7714.7 & 0.002004 & 35.46 \\
\hline 16 & 10080 & 9154.7 & 0.001886 & 33.38 \\
\hline 17 & 11520 & 10594.7 & 0.001790 & 31.67 \\
\hline 18 & 12960 & 12034.7 & 0.001709 & 30.24 \\
\hline 19 & 14400 & 13474.7 & 0.001640 & 29.02 \\
\hline 20 & 15840 & 14914.7 & 0.001580 & 27.95 \\
\hline
\end{tabular}

${ }^{a}$ Assuming nominal reactor power of $1.38 \mathrm{GWth}$ and 78 tons of $\mathrm{UO}_{2}$.

\subsubsection{Simulation Comparison - Similar Modeling Options}

While a number of options have been selected such that the codes use similar modeling options, there are a number of hard-coded or other modeling differences between codes such that the following comparison is not one-to-one. However, the following comparison does illustrate that the codes predict similar results and trends when the codes are set up to use many similar modeling methodologies. The following comparison also illustrates the impact of some of the modeling differences between MELCOR (CORCON-Mod3) and CORQUENCH.

\section{Initial Material Properties}

Table 8 compares in the initial material properties predicted by each respective code for the same melt specified in Table 6 . The predicted density, specific heat, and surface tension are quite similar. There are notable differences in the melt thermal conductivity and viscosity. The difference could be attributed to the thermal conductivity in MELCOR being independent of the melt temperature and/or the differences in constituent weighting (molar vs. volume). The difference in viscosity is attributed to the differences in the internal routines used. The predicted metallic-phase solidus and liquidus temperatures in MELCOR 
are similar to those predicted for the metallic phase in CORQUENCH. The predicted oxidic-phase solidus and liquidus temperatures in MELCOR are higher than those predicted for the oxidic phase in CORQUENCH. This may be due to the inclusion of zirconium as a eutectic species in the oxidic phase in CORQUENCH.

Table 8. Initial melt properties comparison

\begin{tabular}{|l|c|c|c|}
\hline \multicolumn{1}{|c|}{ Melt } & MELCOR & CORQUENCH & Units \\
\hline Mass & 28682 & 28683 & $\mathrm{~kg}$ \\
\hline Density & 7469 & 7303 & $\mathrm{~kg} / \mathrm{m}^{3}$ \\
\hline Specific heat & 559.96 & 528.82 & $\mathrm{~J} / \mathrm{kg} * \mathrm{~K}$ \\
\hline Thermal conductivity & 20.49 & 5.01 & $\mathrm{~W} / \mathrm{m}^{*} \mathrm{~K}$ \\
\hline Viscosity & 0.412 & 1.707 & $\mathrm{~kg} / \mathrm{m} * \mathrm{~s}$ \\
\hline Surface tension & 0.96 & 0.783 & $\mathrm{~N} / \mathrm{m}$ \\
\hline Emissivity & $0.72^{a}$ & 0.715 & - \\
\hline Solidus-oxidic & $2847.6^{\mathrm{b}}$ & 2215.4 & $\mathrm{~K}$ \\
\hline Solidus-metallic & $1741.7^{\mathrm{b}}$ & 1715.1 & $\mathrm{~K}$ \\
\hline Liquidus-oxidic & $2864.3^{\mathrm{b}}$ & 2465.0 & $\mathrm{~K}$ \\
\hline Liquidus-metallic & $1752.2^{\mathrm{b}}$ & 1742.3 & $\mathrm{~K}$ \\
\hline
\end{tabular}

${ }^{a}$ User specified in input.

${ }^{\mathrm{b}}$ The reported solidus and liquidus temperatures for each phase are actually switched in the MELCOR dump file; i.e. the reported liquidus temperature is less than the reported solidus temperature.

\section{Ablation Depth and Profile}

Figure 5 compares the concrete ablation profiles at specific times. CORQUENCH maintains a right cylinder geometry, whereas due to the ray tracking methodology, MELCOR forms a rather large rounded "fillet" between the axial and radial concrete surfaces. Differences in the predicted melt height, which are discussed in the following section, also affect the predicted ablation profile.

Figure 6 compares the maximum predicted radial and axial concrete ablation depths. Early in the transient the two codes predict fairly similar advancement of the axial and radial ablation fronts. From approximately 6-24 hours, MELCOR predicts higher ablation, whereas CORQUENCH begins to reach a quasi-steady state. A few different phenomena contribute to the differences. First, as shown in Fig. 5, MELCOR predicts a growing fillet between the axial and radial concrete surfaces, whereas CORQUENCH maintains the right circular cylinder geometry. The "extra energy" (compared to the nonablated fillet region predicted by MELCOR) that CORQUENCH applies to this corner region to ablate the concrete increases the overall heat loss from the melt, reducing the ablation on the axial and radial walls (in comparison to MELCOR). Second, due to differences in the predicted chemical reactions (in particular the re-oxidation of elemental silicon), more energy is applied to the melt during the 6-12 hour time frame in MELCOR than in CORQUENCH (see Decay Heat and Chemical Reaction Energy section). Third, the slag film model for heat transfer to the concrete (Bradley modification of the KutateladzeMalenkov heat transfer model [49]) has a dependence on the melt thermal conductivity to the one-third power. There is a notable difference in the predicted melt thermal conductivity between MELCOR and CORQUENCH (see Crust Formation and Thermal Conductivity section), which impacts the heat transfer to the concrete (Fig. 7), and therefore the ablation rate. The early peaks in the heat transfer rate into the 
concrete correspond to their respective peaks in heat generation due to chemical reactions (see Decay Heat and Chemical Reaction Energy section).

It is key to point out that both codes predict the melt is not coolable and that the ablation fronts are propagating at similar rates in the long term.

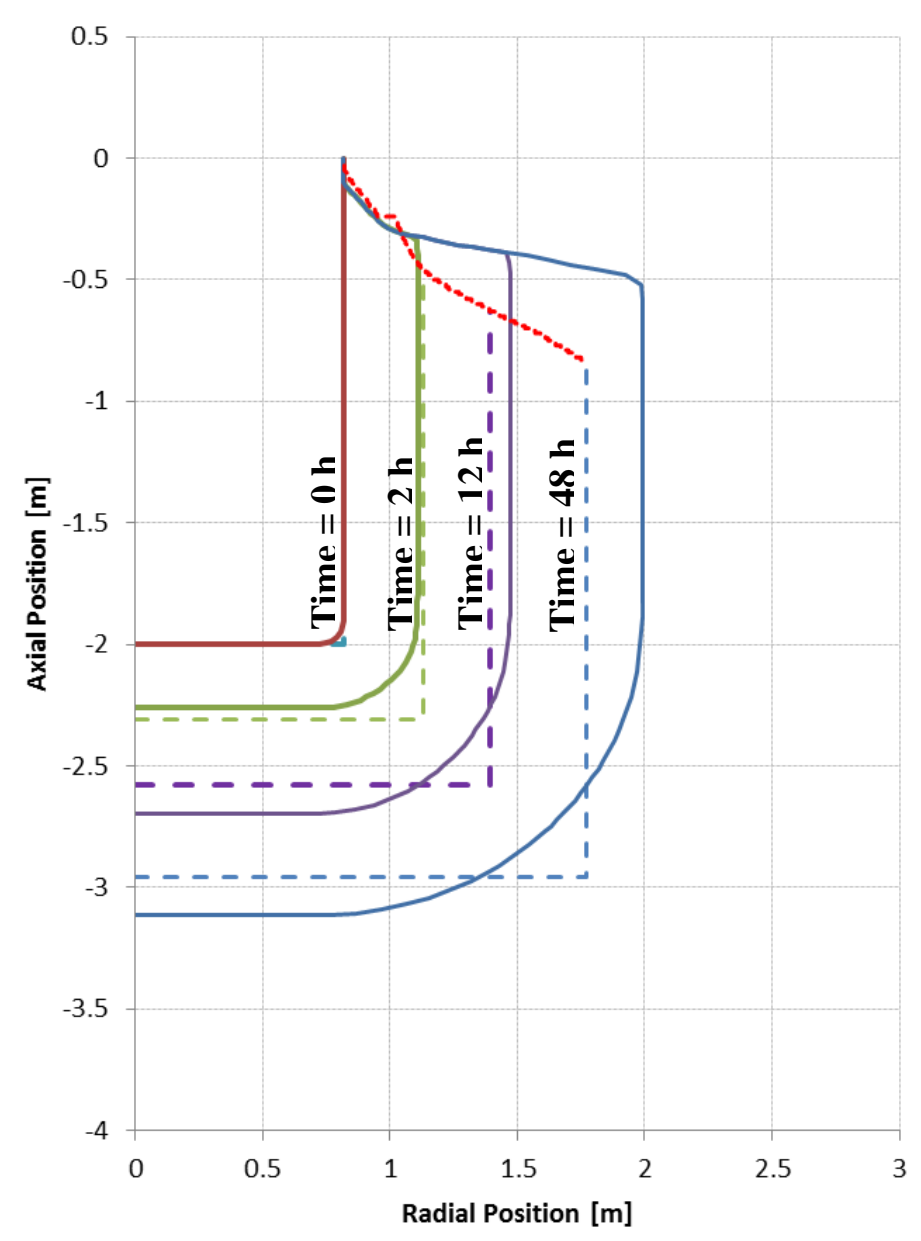

Fig. 5. Concrete ablation profile at $0,2,12$ and 48 hours after melt-concrete contact; CORQUENCH shown using dashed lines; MELCOR shown using solid lines. 


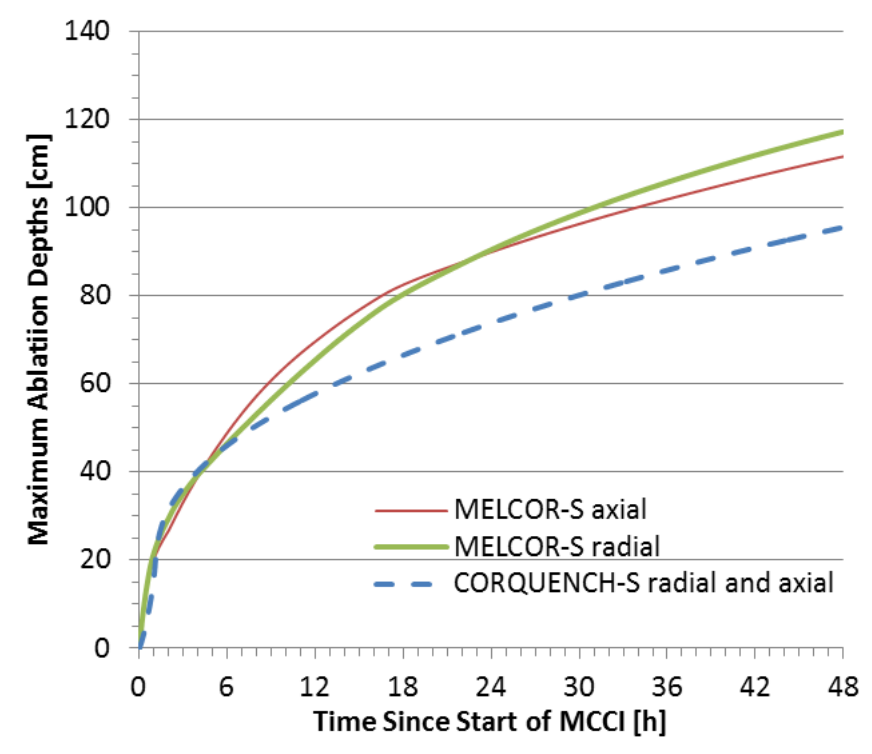

Fig. 6. Radial and axial concrete ablation fronts.

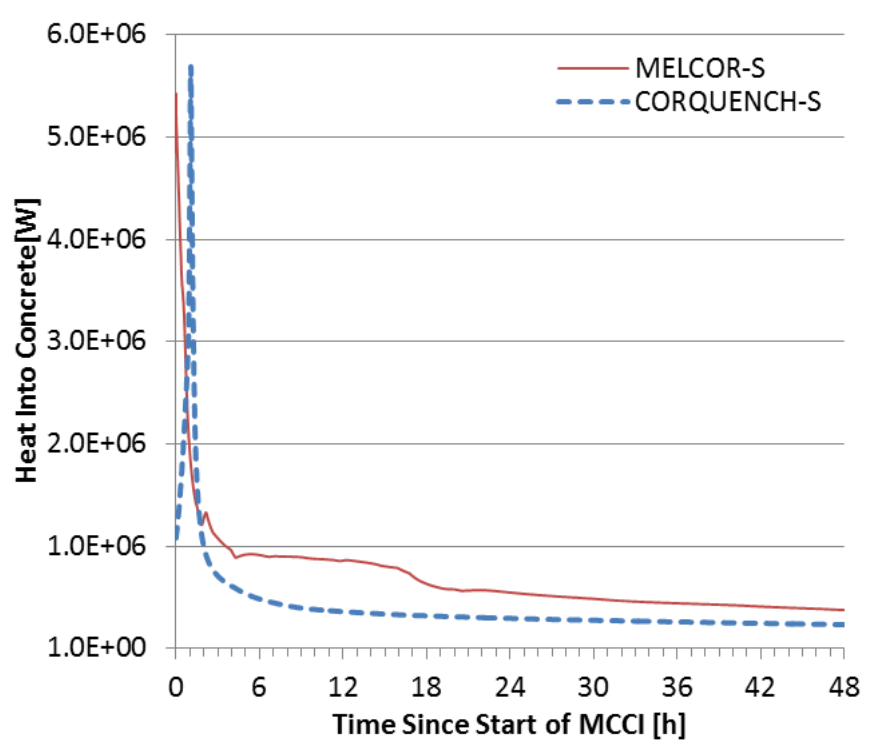

Fig. 7. Heat transfer rate into concrete.

\section{Melt Superficial Gas Velocity and Void Fraction}

There is a significant difference in the predicted pool superficial gas velocity ${ }^{1}$ reported by MELCOR and CORQUENCH (Fig. 8). MELCOR reports two pool superficial gas velocities without clear explanation of the basis for the two. The authors believe they are the superficial gas velocities at the melt pool "inlet" and "outlet." While there is a difference in the ablation rate in the 6-12 hour time frame, the ablation rates, and therefore gas generation rates, are similar at other times (as seen by comparing the slope of the lines in Fig. 6). The cause for the discrepancy in the superficial gas velocities may be due to

\footnotetext{
${ }^{1}$ The superficial gas velocity is defined as the volumetric flow rate of the gas flowing through the pool divided by the top surface area of the pool.
} 
the temperature at which the gas densities are determined. If the two superficial gas velocities reported in the MELCOR output file are indeed at the melt pool "inlet" and "outlet," then the superficial gas velocities would be expected to be lower due to the lower melt pool temperatures at these interfaces in comparison to the bulk melt temperature.

Another potential explanation for the differences in average pool gas sparging rate relates to the way in which the flow paths of gases from concrete decomposition are modeled. In particular, CORQUENCH assumes that gas produced by radial ablation enters the pool where it combines with gas generated by axial ablation to form an average pool gas sparging rate. The sumps in $1 \mathrm{~F} 1$ are quite deep, resulting in significant sidewall surface area (i.e., the initial ratio of sidewall to bottom surface areas is approximately 4.8 given the geometry assumptions outlined above). Thus, in MELCOR if the sidewall gas source is not included in the calculation of average pool sparging rate (i.e., the gas is assumed to vent directly to the containment atmosphere by flow up and along the concrete sidewalls due to the formation of a crust at this interface), then this could explain the discrepancy. The CORCON-Mod3 manual [12] describes the possibility for gas to flow along the sidewall melt-concrete interface; however, it is not clear how the split between gas entering the melt pool versus flowing along the sidewall interface is determined.

There is also a significant difference in the predicted void fraction of the melt (Fig. 9). The Brockmann et al. [41] form of the void fraction model, used by both codes, has a dependence on the superficial gas velocity to approximately the 0.6 power. The void fraction model also has a minor dependence, to the -0.08 power, on the melt viscosity. Therefore, the difference in the predicted pool void fraction is primarily attributed to the discrepancy in the predicted pool superficial gas velocity.

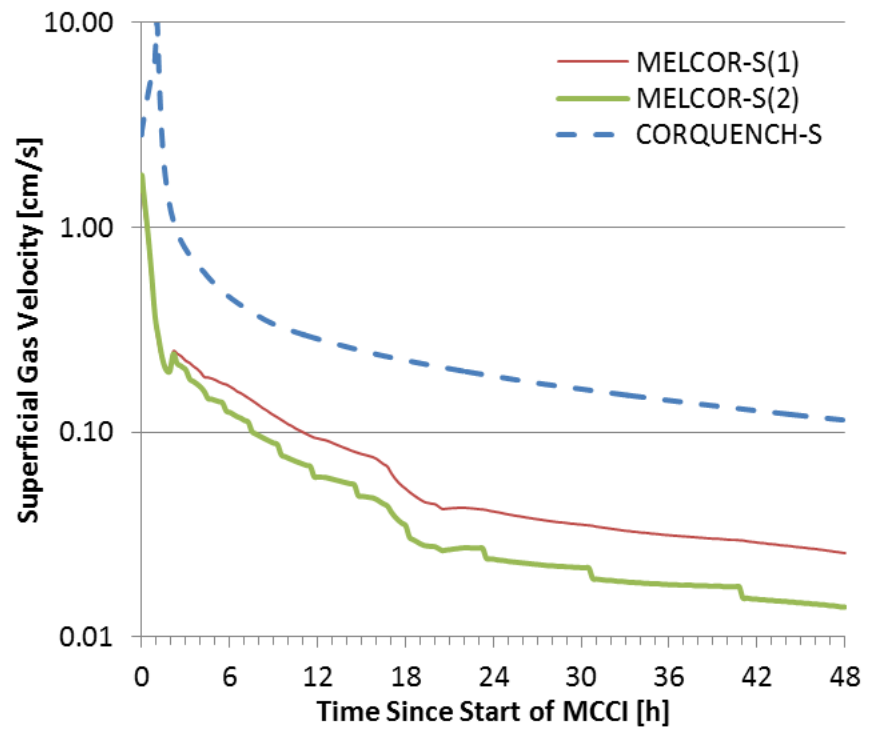

Fig. 8. Superficial gas velocity. 


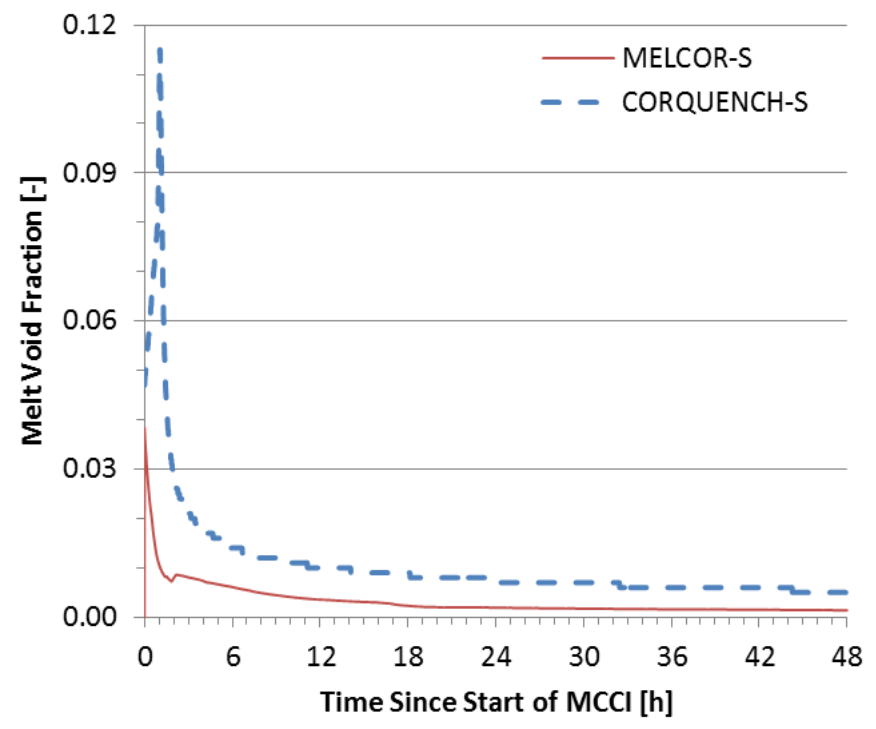

Fig. 9. Melt void fraction.

\section{Crust Formation and Thermal Conductivity}

Figure 10 displays the predicted top crust thickness over time. Figure 11 provides the predicted thermal conductivities for the crust and melt. MELCOR predicts a thicker crust forms on top the melt over time than that predicted by CORQUENCH. The cause for this is explained as follows. First, MELCOR does not track the composition, and associated material properties, of the crusts and melt pool separately. Thus, as the metallic species are oxidized and concrete oxides are added to the melt, the MELCOR crusts, following the melt composition, become increasingly composed of oxides and in particular, concrete oxides. In contrast, the crusts that initially form in CORQUENCH may maintain their metallic constituents and their higher concentration of heavy metal oxides throughout the cooling process. Due to sequestration of $\mathrm{UO}_{2}$ in the crusts early during their formation in CORQUENCH, at later times the volumetric heating of the crusts may be higher than the melt pool which is diluted by concrete oxides. Furthermore, CORQUENCH only models reduction and oxidation reactions occurring in the melt and not in the crust. This assumption is supported by the greater reaction kinetics of the liquid melt in contrast to the solidified crusts. However, as described in the CORCON manual, the volumetic energy source term, accounting for decay and chemical reactions, is set to be equal in the melt and in the crust. The discrepancy in the melt thermal conductivity is attributed to differences in the routine used to determine the thermal conductivity, the treatment of the composition of the melt and crust (both in terms of composition tracking and chemical reactions), the properties used for the individual constituents (CORQUENCH uses temperature dependent properties whereas MELCOR uses temperature independent values).There are additional contributing factors for the discrepancies such as minor differences in the boiling curves used and differences in the predicted bulk melt temperature. 


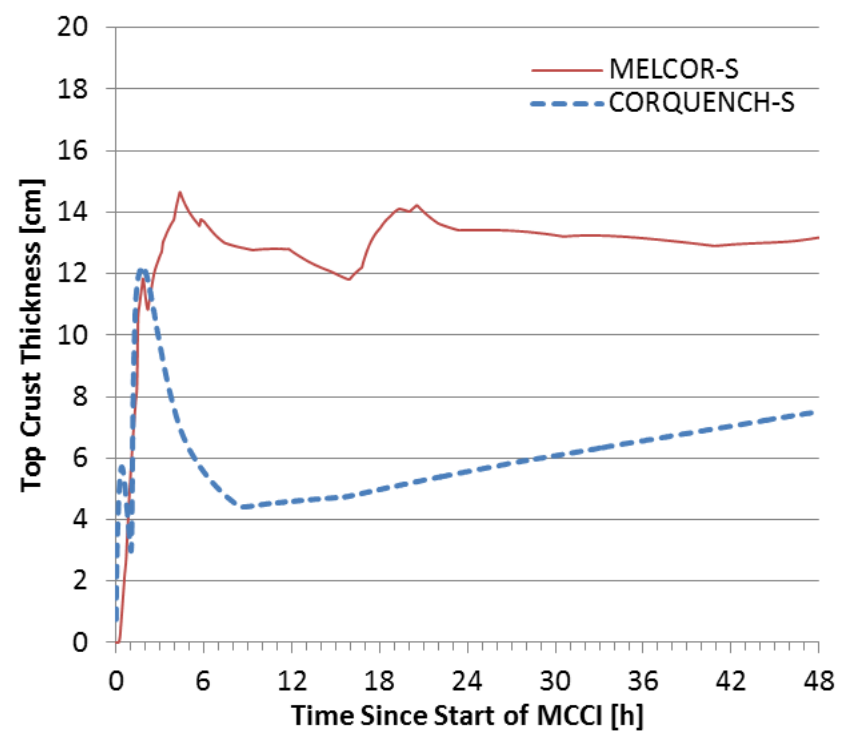

Fig. 10. Top crust thickness.

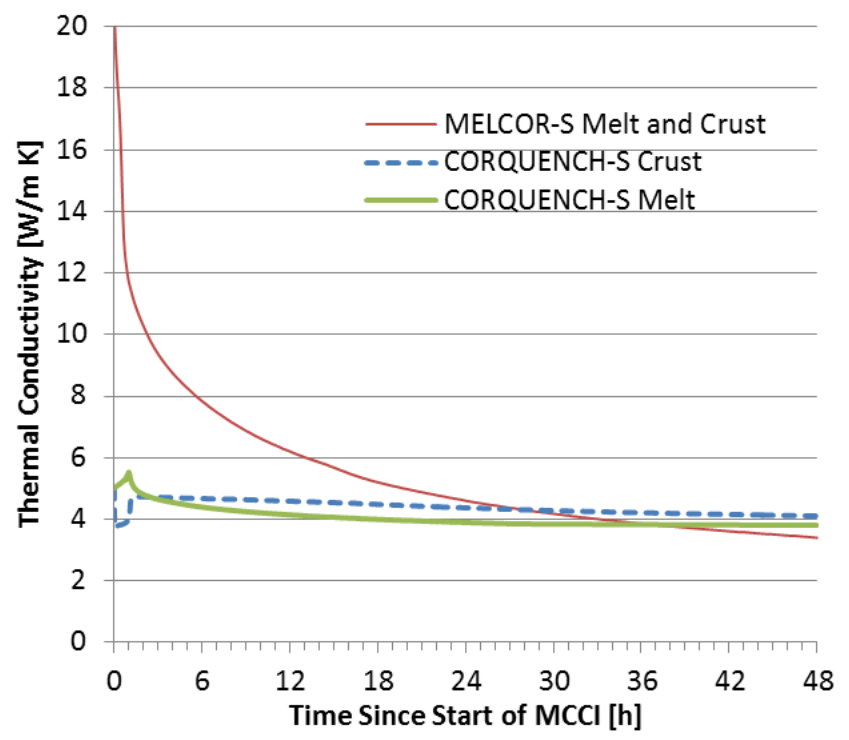

Fig. 11. Crust and melt thermal conductivity.

MELCOR predicted the temporary formation of crusts at the melt-concrete interface (Fig. 12). CORQUENCH can only predict the formation of surface crusts when using the transient concrete dryout and ablation model (the CORQUENCH-S case uses the quasi-steady ablation model to match that used by the MELCOR-S case). 


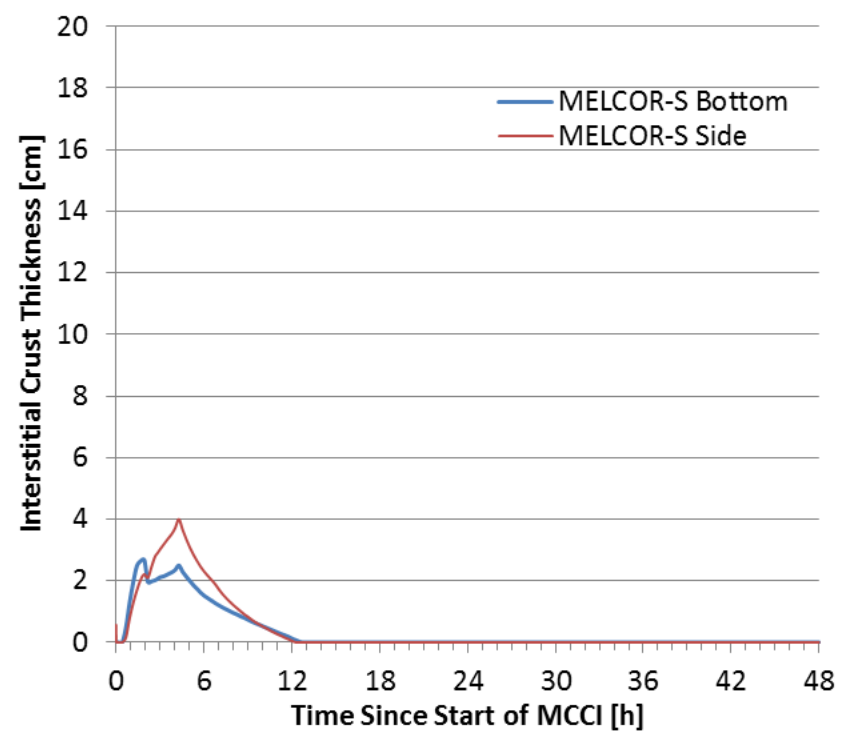

Fig. 12. MELCOR predicted side and bottom crust thicknesses.

\section{Chemical Reactions, Melt Composition, and Combustible Gas Generation}

Figure 13 displays the evolution of the metallic components in the melt over time. In the early phase, lasting less than 3 hours, the zirconium is oxidized. Both codes were set up to account for the condensedphase reaction of silicon dioxide with the zirconium. MELCOR also includes the reduction of the aluminum oxides and uranium oxide during this early phase. Both the metallic aluminum and uranium are then predicted to re-oxidize during this early phase. CORQUENCH does not include the reduction reaction to produce aluminum or uranium and are therefore not predicted to be formed.

Upon completion of the oxidation of the zirconium, MELCOR then predicts the re-oxidation of silicon over the next approximately 13.5 hours. CORQUENCH does not currently account for this reaction, and the silicon remains in the melt. Instead, CORQUENCH begins to oxidize the chromium, whereas the chromium oxidation is delayed approximately 13.5 hours in MELCOR. Finally, after the chromium is oxidized, MELCOR and CORQUENCH oxidize the iron.

A separate simulation was performed in CORQUENCH that neglected the condensed-phase reactions of silicon dioxide with the zirconium. This resulted in a significantly slower oxidation rate of the zirconium and extended out into time the oxidation of the metallic constituents.

The steam and carbon dioxide flowing through the melt from the ablated concrete are reduced by the metallic components in the melt. Figure 14 illustrates the predicted generation of hydrogen and carbon monoxide over the course of the MCCI. CORQUENCH predicts the metallic species in the melt are fully oxidized by approximately 27.5 hours, at which time the generation of combustible gases ceases. MELCOR, which takes into account the re-oxidation of the silicon, predicts that it takes approximately 48 hours to fully oxidize the melt. 

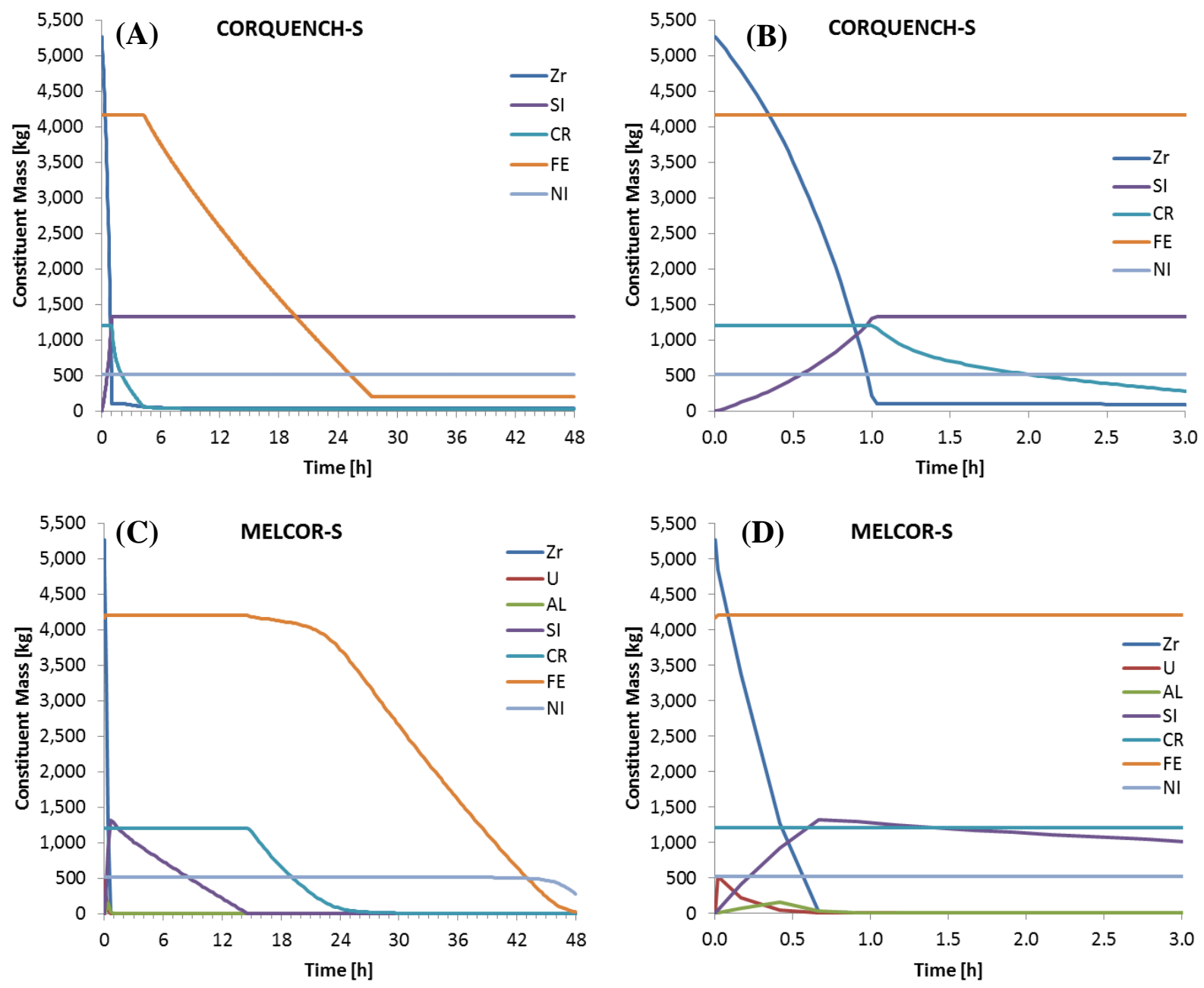

Fig. 13. Melt pool metallic species evolution, $(\mathrm{A}, \mathrm{B})$ CORQUENCH, $(\mathrm{C}, \mathrm{D}) \mathrm{MELCOR}$. 


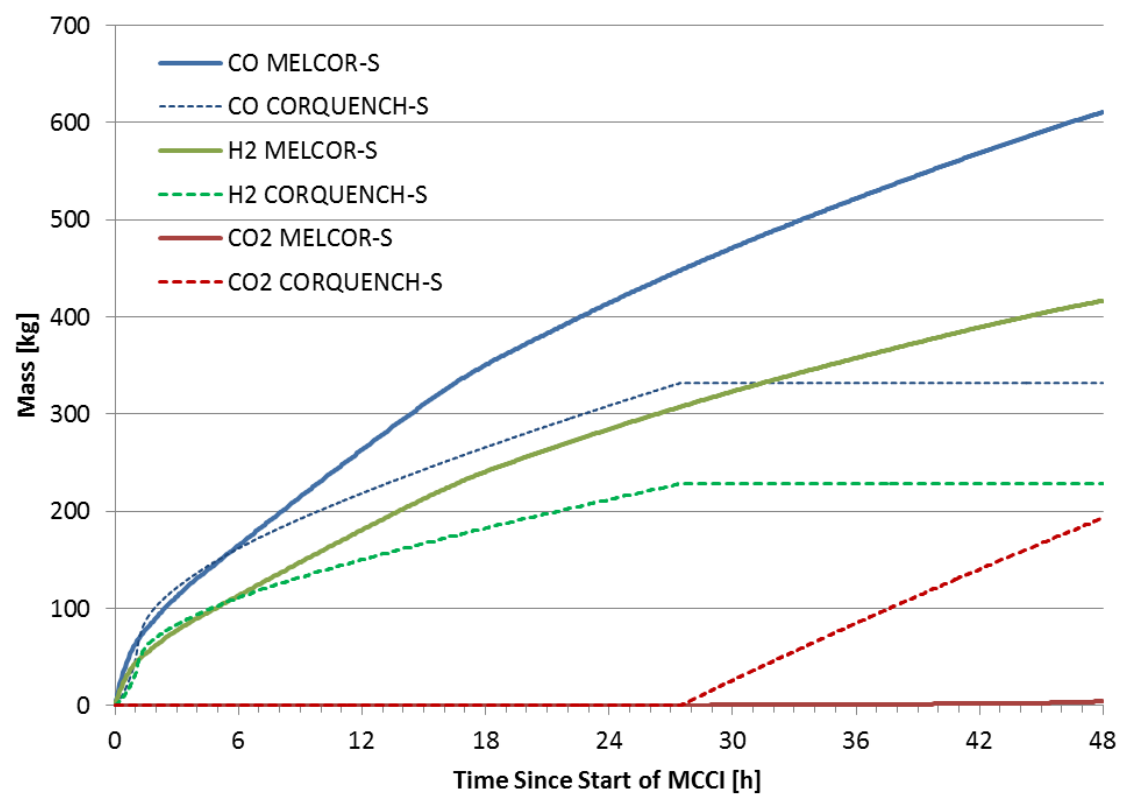

Fig. 14. Combustible gas generation.

\section{Decay Heat and Chemical Reaction Energy}

The total decay heat and predicted heat source due to chemical reactions in the melt pool are shown in Fig. 15. As the decay heat curve was applied to the models, as expected, they are in agreement. Due to differences in the timing and type of chemical reactions taking place in the pool, the energy source terms due to chemical reactions are different. The summation of the decay heat and the heat from the chemical reactions is shown in Fig. 16. Over the time frame of 2-14 hours, during which time MELCOR is reoxidizing the silicon, MELCOR has an initially decreased and then increased energy source term relative to that of CORQUENCH. This corresponds to a period of higher concrete ablation rate as compared to that of CORQUENCH.

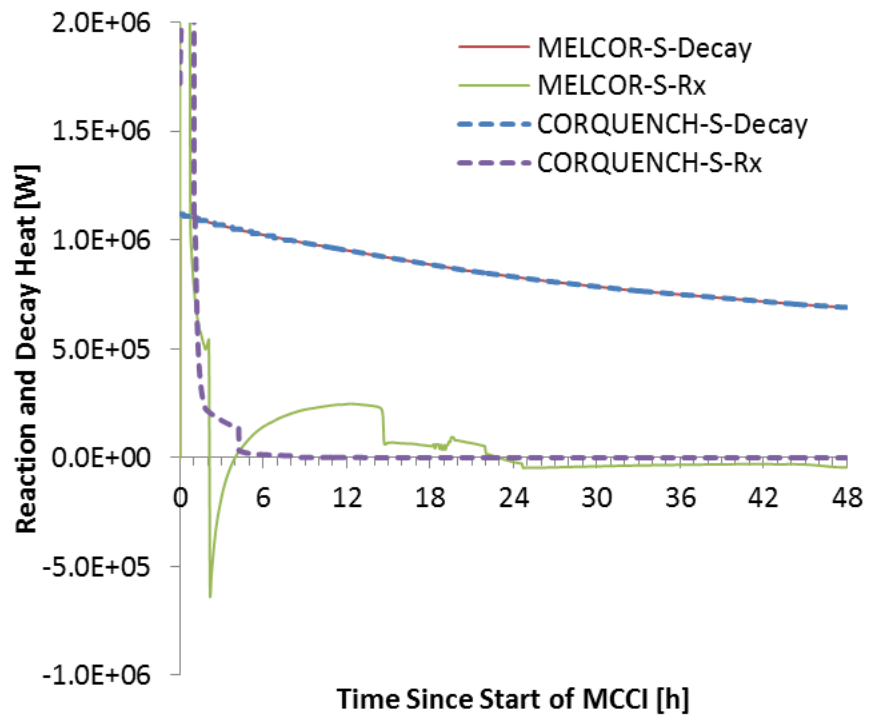

Fig. 15. Decay and chemical reaction heat generation. 


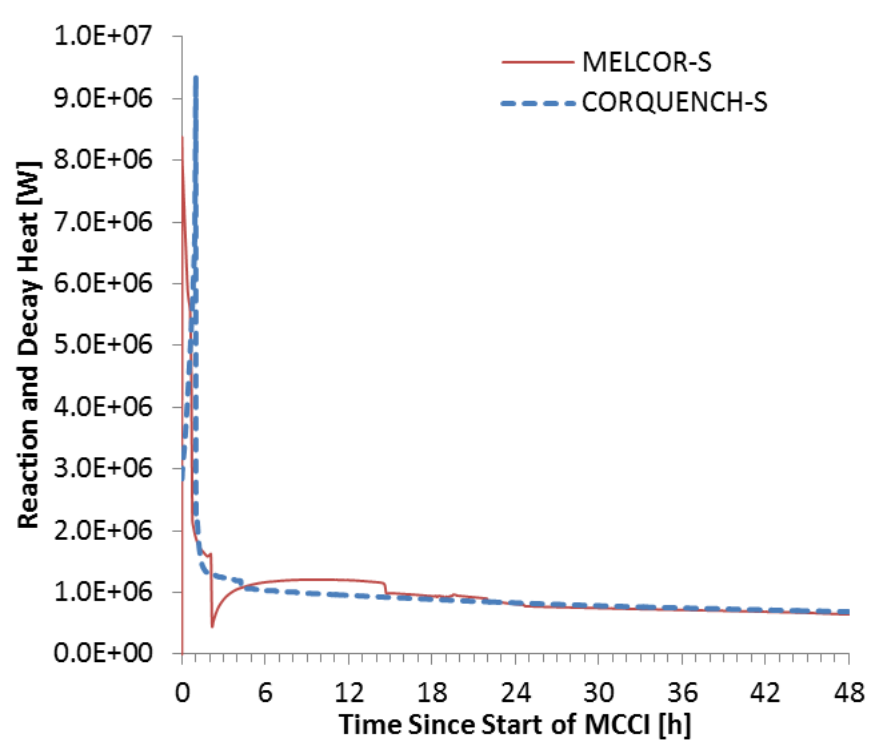

Fig. 16. Combined decay and chemical reaction heat generation.

\section{Melt Pool Bulk Temperature}

The predicted bulk melt pool temperatures are provided in Fig. 17. Included in the figures are the predicted oxide solidus and liquidus temperatures. The cause for the more rapid drop in the oxide solidus temperature in CORQUENCH compared to MELCOR is due to the treatment of the addition of concrete oxides to the melt. The oxide solidus temperature in MELCOR is based on the assumption of an ideal mixture, whereas CORQUENCH, based on the data of Roche et al. [45], accounts for the non-linear effect of the concrete oxides on the suppression of the oxidic-phase solidus temperature. The initial increase in oxide-phase solidus and liquidus temperatures for CORQUENCH reflects the gradual reduction of cladding in the melt due to oxidation; the solidus and liquidus temperatures are calculated according to a pseudo-binary phase diagram for a partially oxidized fuel-clad mixture (Section 3.1.12).
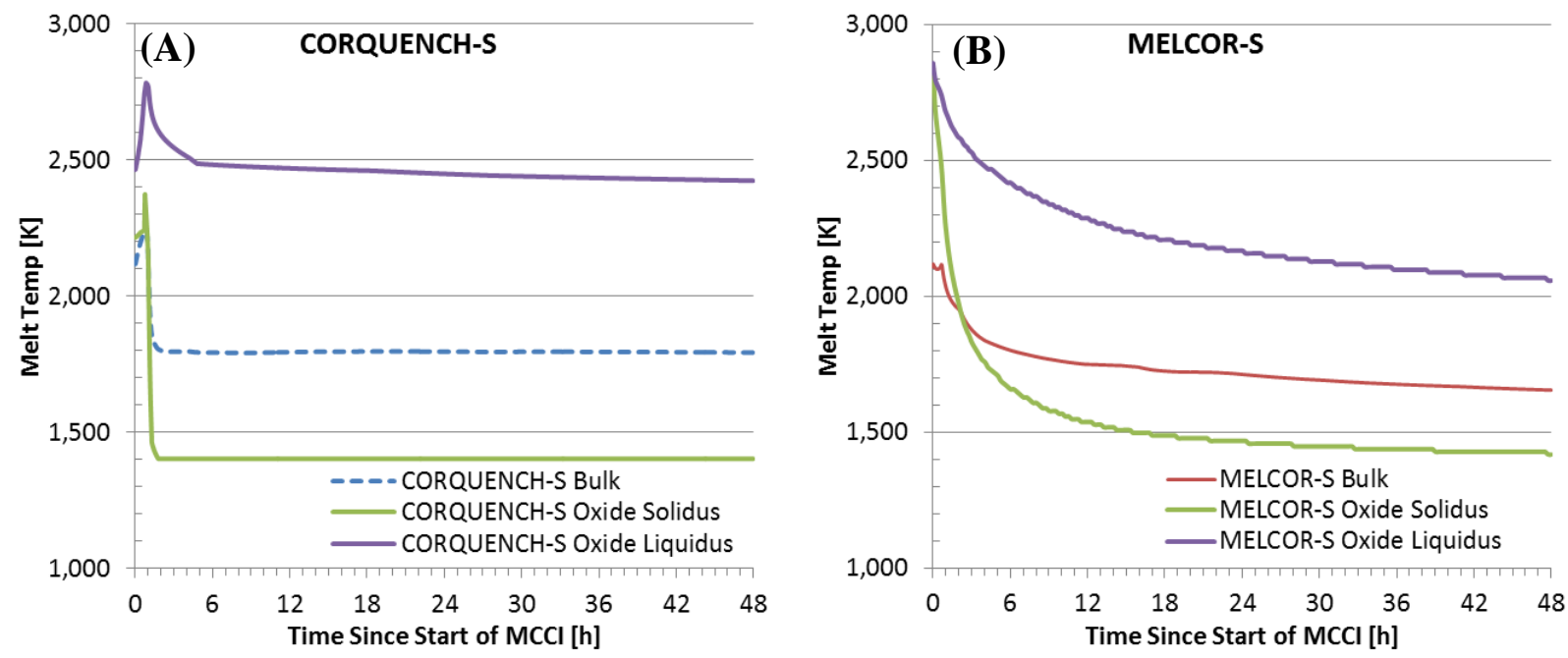

Fig. 17. Predicted bulk melt temperature, (A) CORQUENCH, (B) MELCOR. 


\subsubsection{Simulation Comparison - Best-Estimate Modeling Options}

The following compares the best-estimate predictions by CORQUENCH and MELCOR (cases CORQUENCH-B and MELCOR-B). In general, the predictions are drastically different. CORQUENCH predicts quenching and solidification of the debris in approximately 150 minutes, while MELCOR predicts continued concrete ablation even after 48 hours. A condensed comparison between code results is provided due to the vastly different predictions and associated timescales.

Figures 18 and 19 illustrate the debris axial profile evolution with respect to time. Figure 20 illustrates the cavity ablation profile at the end of the simulations. Due to the user enhancement of the thermal conductivity of the melt by a factor of five, a thicker crust is able to form in MELCOR compared to the case without enhancement (MELCOR-S). However, the conduction-limited crust thickness of approximately $45 \mathrm{~cm}$ is insufficient to result in solidification of the entire melt pool. The additional userdefined enhancement of the boiling curve and melt emissivity are also insufficient to quench the debris. The remaining melt continues to ablate concrete even after 48 hours.

In CORQUENCH, the water ingression model enables water to penetrate the crust, allowing a thicker crust to form. The crust eventually grows large enough to solidify the debris pool, as shown in Fig. 21. The relatively cool melt pour contributes to the rapid solidification of the melt. A hotter melt pour would extend the time until melt solidification. Based on the ANL mechanistic melt eruption model,

CORQUENCH predicts a brief period of melt eruptions, resulting in the formation of a small particle bed for this particular low-gas content concrete type (i.e., Basalt).

Both CORQUENCH and MELCOR predict the formation of interstitial crusts at the melt-concrete interface (Fig. 22). The thermal conductivity of this crust, which is equal to that of the melt in the MELCOR code, was enhanced by a factor of five for the MELCOR-B case. CORQUENCH, which independently tracks the composition of the crusts, has a higher concentration of metallic constituents in the crust, which serves to augment its thermal conductivity in comparison to the increasingly oxidic melt pool.

Figure 23 illustrates the large difference in the predicted amounts of combustible gas generated. CORQUENCH predicts only $16 \mathrm{~kg}$ of $\mathrm{H}_{2}$ and $22 \mathrm{~kg}$ of $\mathrm{CO}$ are generated before the melt solidifies. CORQUENCH does not oxidize metal constituents that are sequestered in frozen material; this accounts for the low-combustible-gas production prediction for this case. In contrast, MELCOR predicts an extended period of concrete ablation and melt oxidation, leading to large quantities of combustible gases being generated. Note, these simulations only model one sump representative of that in $1 \mathrm{~F} 1$ and not the entire melt pool. 


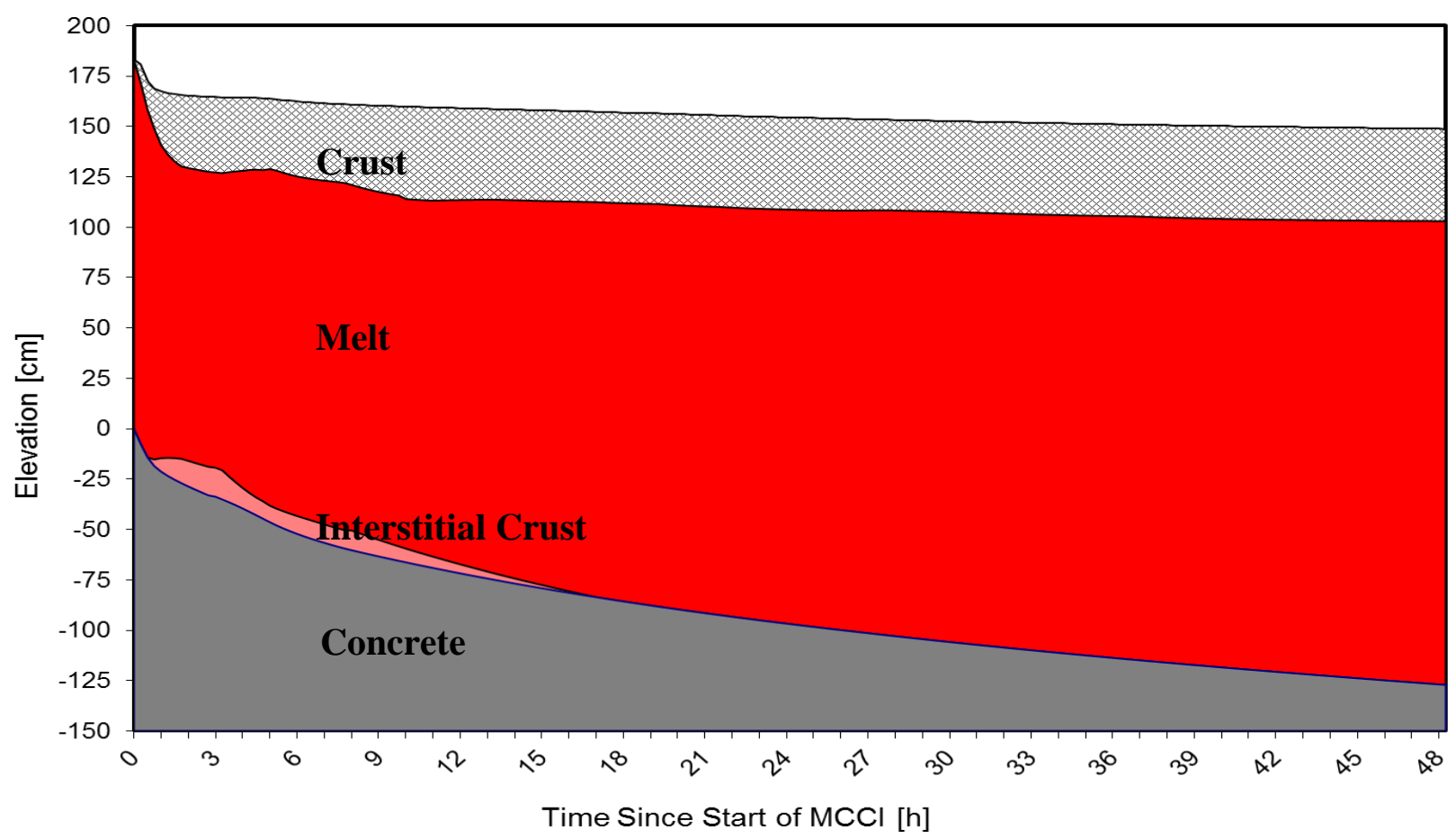

Fig. 18. Debris axial profile evolution, MELCOR-B.

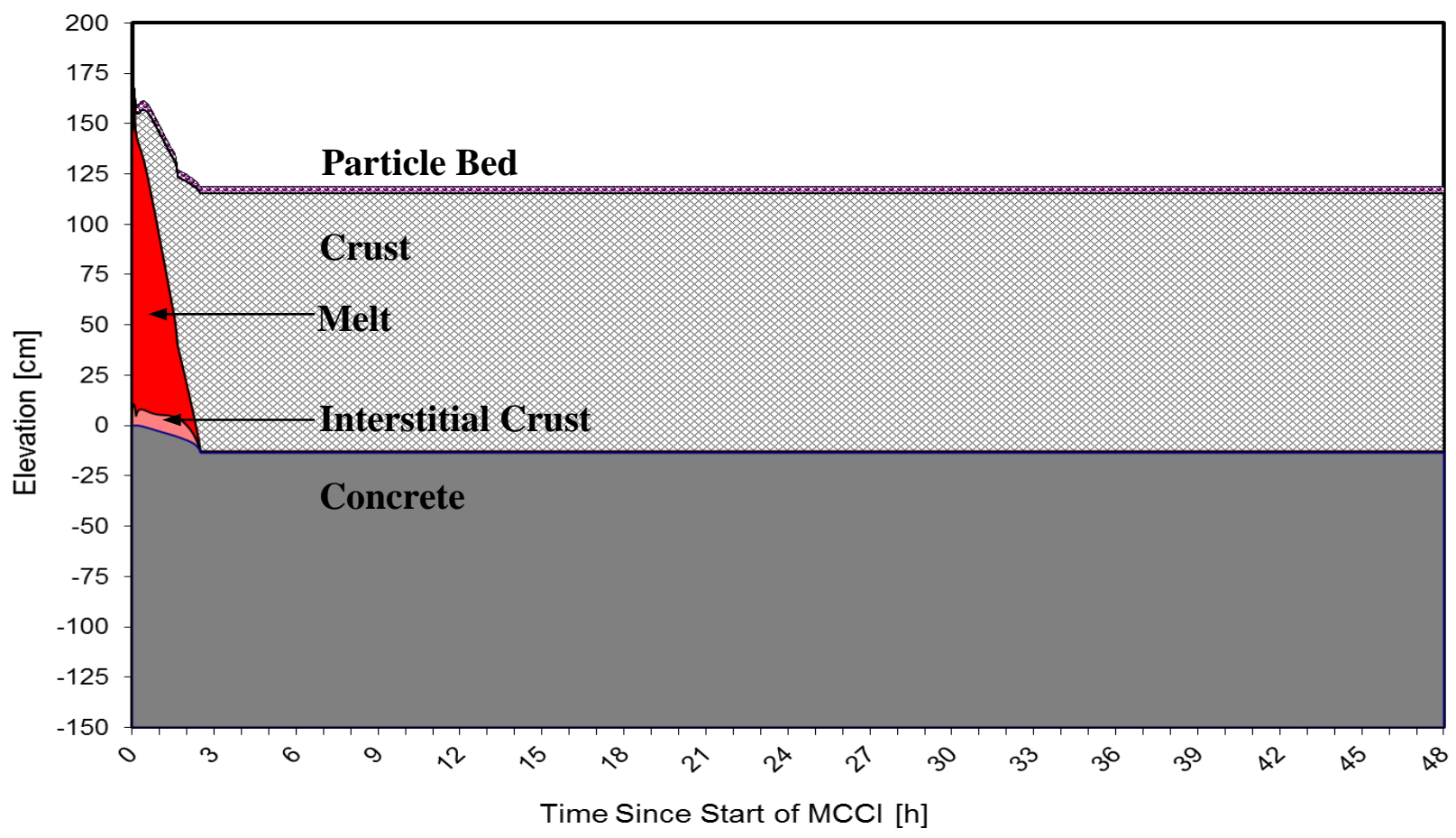

Fig. 19. Debris axial profile evolution, CORQUENCH-B. 


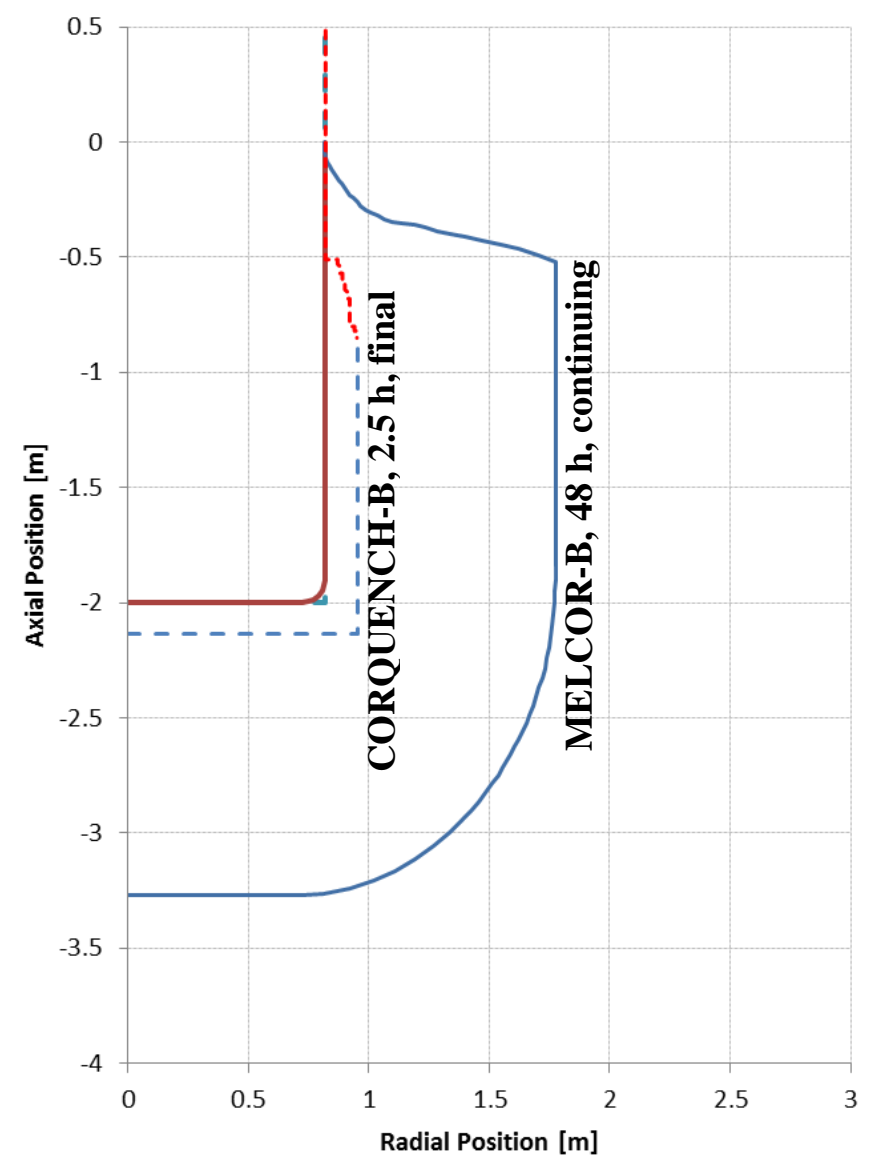

Fig. 20. Ablation profile. 


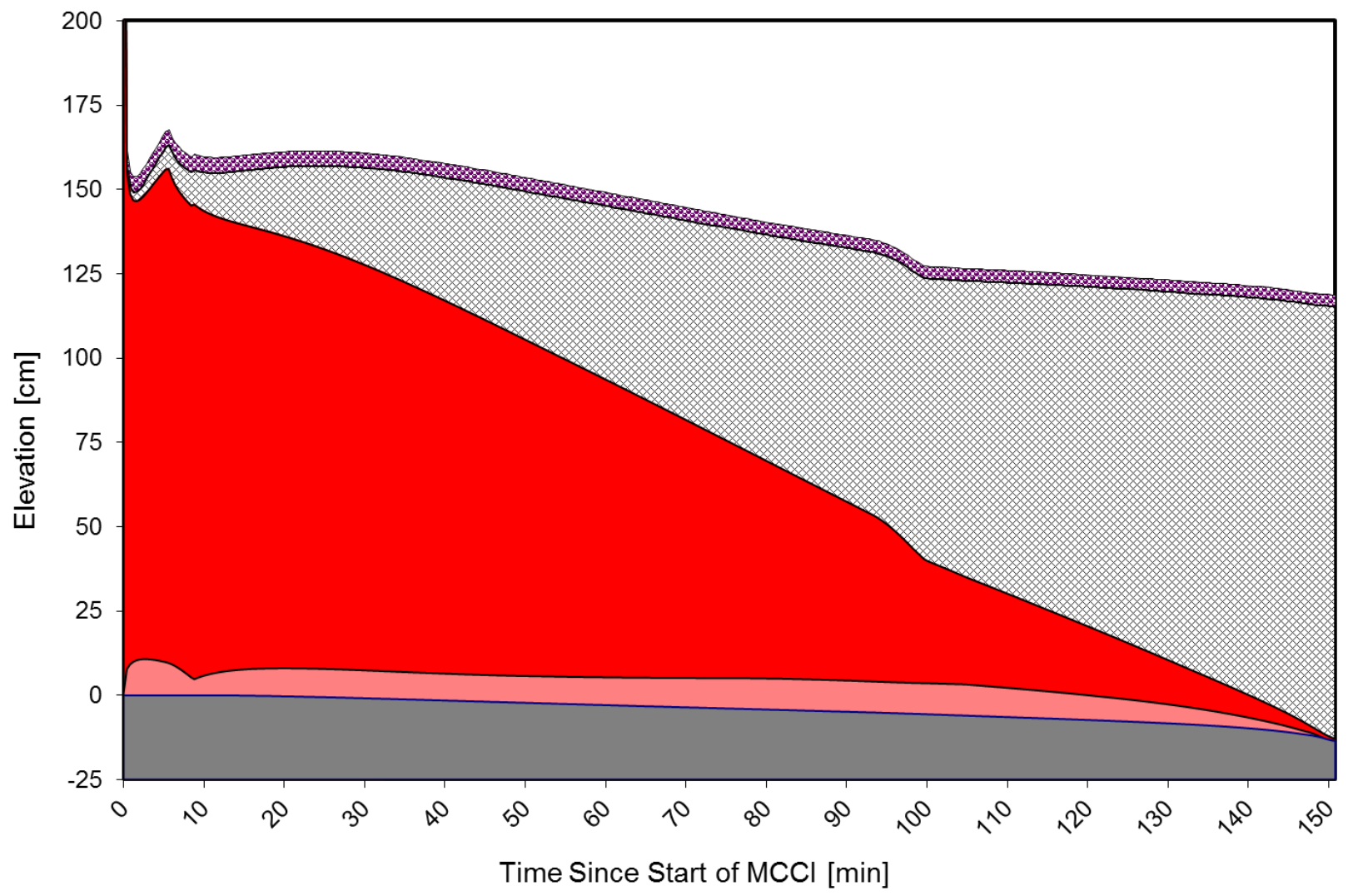

Fig. 21. Debris axial profile evolution, refined plot scale, CORQUENCH-B.

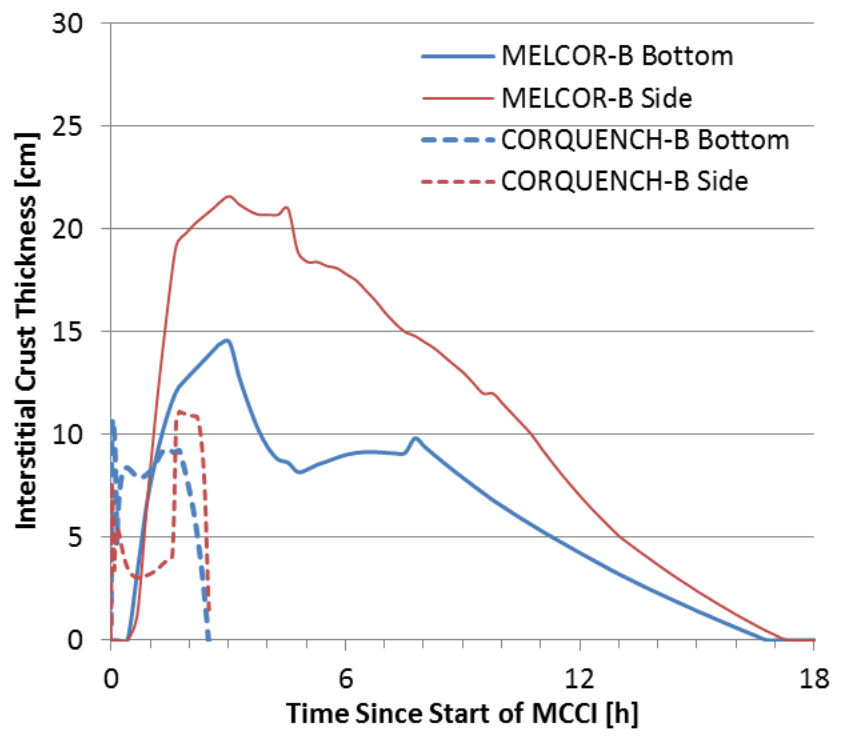

Fig. 22. Interstitial crust thickness. 


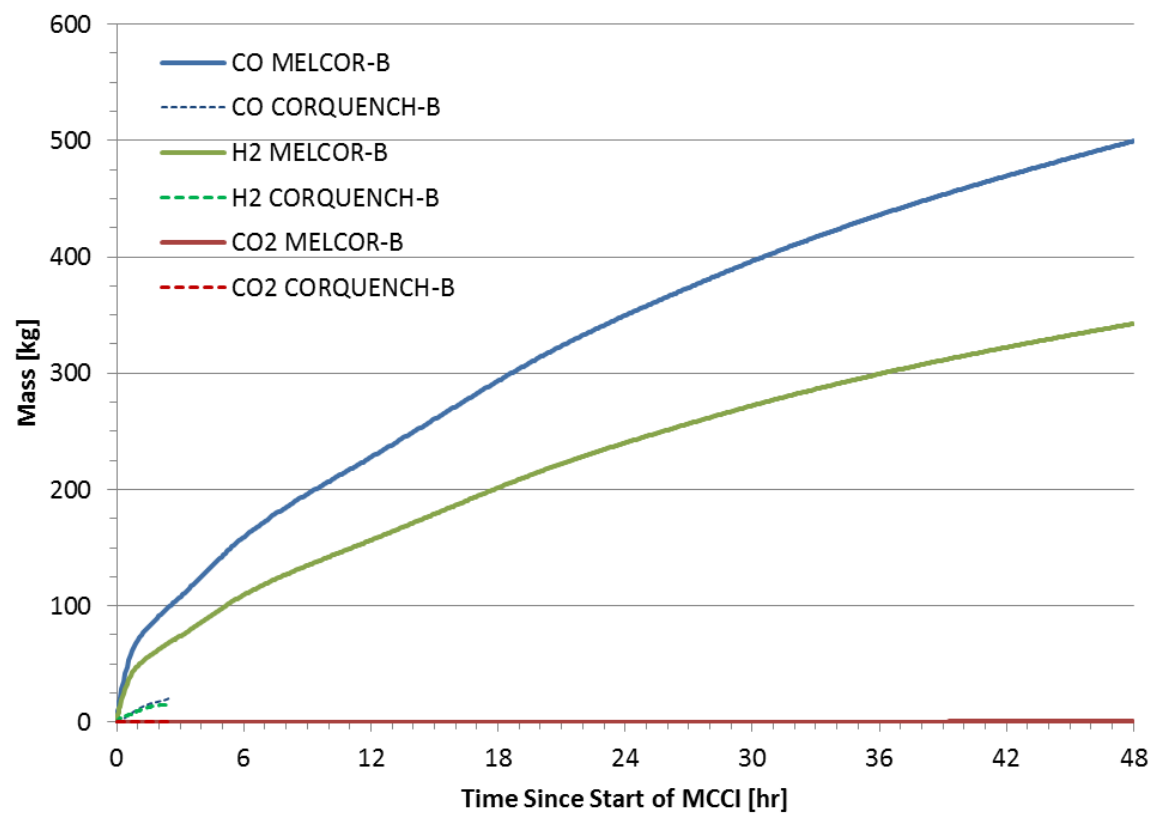

Fig. 23. Gas generation.

\subsection{COMPARISON TO PREVIOUS WORK}

Previously, MCCI predictions from MELCOR and CORQUENCH were compared against one another under similar modeling options and with "advanced modeling options" enabled [20, 21, 50].

Using similar modeling options, the two codes yielded similar results. In contrast, under similar modeling options, the results predicted by the two codes in the current study had a number of minor differences. The previous comparisons were performed for conditions quite different from those predicted for Fukushima Daiichi Unit 1 (summarized in Table 6). In particular, the previous comparisons [20, 21] were performed assuming limestone common sand concrete in contrast to the basaltic concrete at 1F1, an earlier melt pour resulting in higher decay heat levels than at 1F1, a PWR-type melt pour which is lower in zirconium content than a BWR-type melt pour, a shallower melt pool than that predicted for the Fukushima sumps, and a hotter melt pour compared to the $1 \mathrm{~F} 1$ pour conditions predicted by MELCOR. Despite the minor differences in the predicted melt pool behavior, when similar modeling options are used the MELCOR and CORQUENCH codes in both studies predicted the melt was not coolable and both codes predicted similar long-term concrete ablation rates.

In common with the previous comparisons [20,21] and sensitivity studies [41], the water ingression phenomenon modeled in CORQUENCH was again shown in this study to have a large impact on melt coolability. The previous studies also showed that melt eruptions, although less well understood than water ingression, and the crust anchoring phenomenon, modeled in CORQUENCH, could also greatly impact melt coolability.

A comparison of CORQUENCH 3.03, MELCOR/CORCON 1.8.6, and ASTEC/MEDICIS code predictions for a postulated VVER-1000 MCCI scenario was recently performed [51]. In general, the results are in agreement with the current study. Without enabling any enhanced heat transfer models, all three codes predicted that the melt was not coolable within 24 hours of simulation. Increasing the standard boiling curve in CORCON by a factor of five did not result in quenching of the melt. Increasing the thermal conductivity of the melt pool in CORCON by a factor of five did result in the termination of concrete ablation in the study, whereas this modification did not result in coolability in the present work. This is likely due to differences in the melt pool depth between scenarios. Enabling water ingression resulted in melt quenching in the CORQUENCH and ASTEC simulations. Enabling melt eruptions 
resulted in melt quenching in the CORQUENCH simulation but not in the ASTEC simulation. This may be due to difference in melt eruption modeling or other differences between the codes. 


\section{MODELLING ENHANCEMENT RECOMMENDATIONS}

Based on this study several areas for code improvement were identified.

In MELCOR, the current melt spreading modeling is defined by user-defined functions. This allows the user flexibility. The model reviewed uses the concrete liquidus and solidus temperatures as surrogates for the melt liquidus and solidus temperatures as the melt liquidus and solidus are not parameters that have been made available to the user. It is recommended the melt properties, including the solidus, liquidus, density and viscosity, be made available to the user for their inclusion in the user-defined melt spreading modeling. With regards to long-term melt coolability, it is recommended to update the CORCON-Mod3 module within MELCOR to include a water ingression and melt eruption model due to their large impact on coolability as demonstrated by experiments. Including a melt eruption model would necessitate the inclusion of a particle bed layer on the top crust and the appropriate heat transfer/dry-out models. In addition, due to the prevalence in past experiments, including a crust anchoring model would aide in the validation of the CORCON modeling methodology against the existing experimental database. Currently, MELCOR only tracks one composition for the debris. The ability to independently track the composition of the melt and top, bottom, and side crusts would enhance the accuracy of the predicted crust thickness and dissolution. The bottom and side crusts decrease ablation and may affect ablation anisotropy and the top crust impacts melt coolability. Finally, it is recommended that CORCON-Mod3 be updated to include $\mathrm{B} 4 \mathrm{C}$ as one of the melt constituents.

MELTPSREAD serves the purpose of mapping the process of the core melt relocation from the RPV into containment while accounting for geometrical aspects of the containment geometry as well as flow and freezing effects. One aspect of this process involves fragmentation and cooling of the core debris as it falls through the water pool over the containment basemat, should water be present. Currently, MELSPREAD does not analyze melt stream breakup through water, and therefore the code most likely over-predicts the extent of spreading. From the viewpoint of debris coolability, this is not conservative as the further the melt spreads, the shallower the final pool depth will be. Thus, one recommended upgrade for MELTSPREAD is to incorporate a melt stream breakup model.

With regard to CORQUENCH, it is recommended to expand the treatment of chemical reactions to include the oxidation of elemental silicon and nickel. A higher fidelity concrete ablation profile tracking routine, using either the ray tracing routine in CORCON or by discretizing the melt, would allow for more accurate prediction of the ablation profile and, as applicable, basemat melt-through times.

Finally, it should be noted that the study found differences in spreading behavior, most notably the shell contact and heatup, between the containment design of Peach Bottom compared to that of Fukushima Daiichi Unit 1 (see Table 2, Fig. 3 and Fig. 4). Also, while not shown in this study, based on the authors' experience the difference in sump depths between the two containment designs (see Table 2) would affect the amount of concrete ablation and the long-term coolability of the debris. Previously, the Peach Bottom containment design was used in the modeling of 1F1 [1]; however, it is recommended that the containment design of $1 \mathrm{~F} 1$ is taken into account in future modeling activities. 


\section{SUMMARY AND CONCLUSIONS}

System-level code analyses by both United States and international researchers predict major core melting, bottom head failure, and corium-concrete interaction for Fukushima Daiichi Unit 1. Although system codes such as MELCOR and MAAP are capable of capturing a wide range of accident phenomena, they currently do not contain detailed models for evaluating some ex-vessel core melt behavior. However, specialized codes containing more detailed modeling are available for melt spreading — such as MELTSPREAD — as well as long-term molten corium-concrete interaction (MCCI) and debris coolability - such as CORQUENCH.

This report investigated the differences in the treatment of the ex-vessel melt, with respect to melt spreading and long-term coolability, of the MELCOR v2.1 code compared to the MELTSPREAD and CORQUENCH 3.03 codes. The differences in modeling approaches were summarized, and a comparison of example code predictions was provided.

Regarding melt spreading, MELTSPREAD includes relatively detailed modeling of core debris relocation including fluid-mechanics effects, heat transfer to overlying water and underlying concrete, and finally mechanistically calculated solidification at the debris leading edge. In contrast, the MELCOR code predicts the melt spread area through the use of a mass balance and a user-specified hydraulic relationship which spreads the melt based on the melt height and temperature. Despite the major differences in modeling approaches, the overall differences in predicted spreading behavior between the two codes are not that large; that is, MELCOR predicts melt accumulation and spreading out of the pedestal doorway at 194 seconds, whereas MELTSPREAD predicts earlier penetration into the drywell at 98 seconds. By the end of the spreading transient, MELCOR predicts $38 \mathrm{~m}^{2}$ of total floor area coverage, which is $21 \%$ more than MELTSPREAD (i.e., $31.4 \mathrm{~m}^{2}$ ). Although agreement for this particular 1F1 sequence is reasonable, it is not clear from this study how well the two codes would compare under a different set of conditions.

Regarding modeling of long-term core-concrete interaction behavior and debris coolability, MELCOR and CORQUENCH share many common elements but deviate in the following areas: (i) MELCOR has a sophisticated cavity profile erosion model, whereas CORQUENCH uses a highly simplified 2-D cavity profile model; (ii) the MELCOR metal oxidation models are more sophisticated in comparison to CORQUENCH; and (iii) MELCOR does not currently contain debris cooling models that can calculate quench and thermal stabilization of core debris following cavity flooding; in contrast, CORQUENCH includes relatively sophisticated models for calculating core debris cooling by melt eruption and water ingression cooling mechanisms. The two codes were first applied under a similar set of modeling conditions to the 1F1 sump configuration (i.e., quasi-steady concrete ablation models invoked with no melt coolability models invoked). Under these conditions, the two codes were found to produce quite similar trends in cavity erosion behavior over 48 hours. This demonstrates that the codes can produce similar results using similar options. The differences are primarily related to the way in which condensed-phase chemical reactions between cladding and silica materials arising from coreconcrete interaction are treated. It is important to note that with melt coolability models disabled, both codes predict ongoing core-concrete interaction after 48 hours with eventual basemat penetration. With coolability models invoked, CORQUENCH predicts relatively rapid debris quenching and stabilization of the core debris in the 1F1 sump after approximately 150 minutes. In contrast, MELCOR, even with heat transfer enhancements (increasing boiling curve and melt and crust thermal conductivity), predicts continued concrete erosion in the $1 \mathrm{~F} 1$ sump. The coolability models incorporated into CORQUENCH are based on experimental and modeling work performed after CORCON-Mod3 was developed and integrated into MELCOR. These coolability phenomena and models have been shown to have an important impact on the MCCI progression. The inclusion of these models into codes, such as CORQUENCH, provides for more realistic predictions of MCCI progression.

Finally, based on a comparison of the codes a number of updates were identified and recommended. As noted in the introduction, efforts are currently underway to update MAAP [9] and MELCOR [10, 11]. It is recommended that models for water ingression, melt eruption, and crust anchoring be added to 
MELCOR. For use in developing a spreading model, it would be useful to the MELCOR user if the melt properties, such as the solidus and liquidus temperatures, were accessible. Adding the ability in MELCOR to independently track the composition of the top, bottom and side crusts would facilitate more accurate prediction of the crust thicknesses and related heat transfer. Adding a melt stream breakup model through water to MELTSPREAD, to be used during melt relocation, would provide for more accurate determination of the extent of melt spreading and post-spreading debris depth important with respect to long-term debris coolability. It is recommended to expand the treatment of chemical reactions in CORQUENCH to include the oxidation of elemental silicon and nickel. Finally, it was found that differences in containment designs between Peach Bottom and 1F1 had an effect on melt spreading and likely the debris cooling in the sumps. Therefore, it is recommended that the actual containment characteristics of $1 \mathrm{~F} 1$ be taken into account in future modeling activities. 


\section{REFERENCES}

1. R.O. Gauntt, D. A. Kalinich, J. Cardoni, A. Goldmann, J. Phillips, S. Pickering, C. Smith, S. St. Germain, D. Schwieder, C. Phelan, M. W. Francis, K. R. Robb, L. J. Ott, and D. Wang, "Fukushima Daiichi Accident Study," SAND2012-6173 (July 2012).

2. D. Luxat, J. Gabor, R. Yang, F. Rahn, Fukushima Technical Evaluation: Phase 1 - MAAP5 Analysis, EPRI Technical Report 1025750 (April 2013).

3. Nuclear Emergency Response Headquarters, Government of Japan, Report of Japanese Government to the IAEA Ministerial Conference on Nuclear Safety - The Accident at TEPCO's Fukushima Nuclear Power Stations (June 2011).

4. Tokyo Electric Power Company Inc. (TEPCO), "The Evaluation Status of Reactor Core Damage at Fukushima Daiichi Nuclear Power Station Units 1 to 3," press release handout, Nov. 30, 2011.

5. M. T. Farmer, J. J. Sienicki, and B. W. Spencer, "The MELTSPREAD-1 Computer Code for the Analysis of Transient Spreading in Containments," Proceedings of ANS Winter Meeting, Washington D.C., Nov. 11-15, 1990.

6. M. T. Farmer, J. J. Sienicki, C. C. Chu, and B. W. Spencer, The MELTSPREAD-1 Code for Analysis of Transient Spreading and Cooling of High-Temperature Melts, Code Manual, EPRI TR-103413 (1993).

7. M. T. Farmer, The CORQUENCH Code for Modeling of Ex-Vessel Corium Coolability under Top Flooding Conditions, Code Manual - Version 3.03, OECD/MCCI-2010-TR03, Draft March (2010).

8. K. R. Robb, M. W. Francis, and M. T. Farmer, Enhanced Ex-Vessel Analysis for Fukushima Daiichi Unit 1: Melt Spreading and Core-Concrete Interaction Analyses with MELTSPREAD and CORQUENCH, ORNL/TM-2012/455 (February 2013).

9. Q. Zhou, C. Y. Paik, "Benchmark of MCCI Model in MAAP5.02 against OECD CCI Experiment Series," Proc. of ICAPP 2014, Charlotte, USA, April 6-9, 2014.

10. L. Humphries, "MELCOR Code Development Status," Proc. of CSARP 2013, Bethesda, Maryland, USA, Sept. 17-20, 2013.

11. U.S. Nuclear Regulatory Commission, "Consideration of Additional Requirements for Containment Venting Systems for Boiling Water Reactors with Mark I and Mark II Containments," SECY-12-0157, March 19, 2013.

12. D. R. Bradley, D. R. Gardner, J. E. Brockmann, and R. O. Griffith, CORCON-Mod3: An Integrated Computer Model for Analysis of Molten Core-Concrete Interactions, NUREG/CR-5843 (October 1993).

13. M. T. Farmer, D. J. Kilskonk, and R. W. Aeschlimann, "Corium Coolability Under Ex-Vessel Accident Conditions for LWRs," Nuclear Engineering and Technology, 41, 5 (2009).

14. M. T. Farmer and S. Basu, "Melt Spreading Code Assessment, Modifications, and Initial Applications to the EPR Core Catcher Design," Proceedings ICAPP '09, Tokyo, Japan (2009).

15. C. Journeau, J.-F. Haquet, B. Spindler, C. Spengler, and J. Foit, "The VULCANO VE-U7 Corium Spreading Benchmark," Progress in Nuclear Energy, 48, 215 (2006).

16. M. Ishii and N. Zuber, "Drag Coefficient and Relative Velocity in Bubbly, Droplet or Particulate Flows," AlChE Journal, 25, 843 (1979).

17. M. Ramacciotti, C. Journeau, F. Sudreau, and G. Cognet, "Viscosity Models for Corium Melts," Nuclear Engineering and Design, 204, 377 (2001).

18. D. Kalinich, Sandia National Laboratory, personal communication to K. R. Robb, Oak Ridge National Laboratory, September 25, 2013.

19. Sandia National Laboratories, MELCOR Computer Code Manuals, Version 2.1, NUREG/CR6119, Rev. 4, Draft. 
20. K. R. Robb and M. L. Corradini, "MCCI Simulation Comparison Between MELCOR and CORQUENCH," Proc. of NURETH-14, ANS, Toronto, Canada, paper 289, September 25-30, 2011.

21. K. R. Robb and M. L. Corradini, "Ex-Vessel Core Melt Coolability Simulation with CORQUENCH and MELCOR," Proc. of OECD/NEA MCCI Seminar 2010, Cadarache, France, paper S5.2, November 15-17, 2010.

22. S. Lomperski and M. T. Farmer, "Experimental Evaluation of the Water Ingression Mechanism for Corium Cooling," Nucl. Eng. Design, 237, 905 (2006).

23. S. W. Jones, M. Epstein, S. G. Bankoff, and D. R. Pedersen, "Dryout Heat Fluxes in Particulate Beds Heated Through the Base," Journal Heat Trans. 106, 176 (1984).

24. S. Lomperski and M. T. Farmer, "Experimental Evaluation of the Water Ingression Mechanism for Corium Cooling," Nucl. Eng. Design, 237, 905 (2006).

25. S. Lomperski, M. T. Farmer, and S. Basu, "Experimental Investigation of Corium Quenching at Elevated Pressure," Nucl. Eng. Design, 236, 2271 (2006).

26. F. B. Ricou and D. B. Spalding, "Measurements of Entrainment of Axisymmetrical Turbulent Jets," J. Fluid Mechanics, 11, 21 (1961).

27. M. T. Farmer, "Phenomenological Modeling of the Melt Eruption Cooling Mechanism During Molten Corium Concrete Interaction (MCCI)," Proceedings ICAPP '06, Reno, Nevada USA, June 6-8, 2006.

28. B. Tourniaire, J. M. Seiler, and J. M. Bonnet, "Experimental Study and Modelling of Liquid Ejection through Orifices by Sparging Gas," Nucl. Eng. Design, 236(19-21), 2281-95 (2006).

29. K. R. Robb and M. L. Corradini, "Melt Eruption Modeling for MCCI Simulations," Proc. of NURETH-14, ANS, September 25-30, Toronto, Canada, paper 290 (2011).

30. W. M. Rohsenow, "A Method of Correlating Heat Transfer Data for Surface Boiling Liquids," Transactions of ASME, 74, 969 (1952).

31. H. J. Ivey and D. J. Morris, "Critical Heat Flux of Saturation and Subcooled Pool Boiling in Water at Atmospheric Pressure," Proceedings 3rd Int. Heat Trans. Conf., 3, 129 (1966).

32. N. Zuber, "On the Stability of Boiling Heat Transfer," Transaction of ASME, 80, 711 (1958).

33. Sandia National Laboratories, "State-of-the-Art Reactor Consequence Analysis Project, MELCOR Best Modeling Practices," NUREG/CR-7008, Rev 1, Predecisional Draft, July (2010).

34. K. Lichteneker, "The Electrical Conductivity of Periodic and Random Aggregates," Physikallsche Zeitschrift, 27, 115 (1926).

35. J. Kendell and K. P. Monroe, "The Viscosity of Liquids, IIl Ideal Solution of Solids in Liquids," Journal of the American Chem. Sot., 39(9), 1802 (September 1917).

36. G. Nazare, G. Ondracek, G., and B. Shulz, "Properties of Light Water Reactor Core Melts," Nuclear Technology, 32, 239 (1977).

37. H. R. Shaw, "Viscosities of Magmatic Silicate Liquids: An Empirical Method of Prediction," American J. of Science, 272, 870 (1972).

38. M. Kunitz, "An Empirical Formula for the Relationship between Viscosity of Solution and Volume of Solute," J. General Physiology, 9, 715 (1926).

39. M. Ishii and N. Zuber, "Drag Coefficient and Relative Velocity in Bubbly, Droplet, or Particle Flows," AIChE Journal, 25, 843 (1979).

40. S. Lomperski and M. T. Farmer, "Corium Crust Strength Measurements," Nucl. Eng. Design, 238, 2551 (2009).

41. J. E. Brockmann, F. E. Arellano, and D. A. Lucero, "Validation of Models of Gas Holdup in the CORCON Code," NUREG/CR-5433 (1989).

42. G. B. Wallis, One-Dimensional Two-Phase Flow, 2nd Ed., McGraw Hill, New York, 1979.

43. Kataoka and M. Ishii, "Drift Flux Model for Large Diameter Pipe and New Correlation for Pool Void Fraction," Int. J. Heat Mass Transfer, 30, 1927 (1987).

44. W. A. Lambertson and M. H. Mueller, "Uranium Oxide Phase Equilibrium Systems: III, $\mathrm{UO}_{2}-\mathrm{ZrO}_{2}$," J. Am. Ceram. Soc., 36, 365 (1953). 
45. M. F. Roche, L. Leibowitz, J. K. Fink, and L. Baker, Jr., "Solidus and Liquidus Temperatures of CoreConcrete Mixtures,"NUREG/CR-6032 (1993).

46. Y. Chevalier, E. Fischer, and B. Cheynet, "Progress in the Thermodynamic Modeling of the O-U-Zr Ternary System," Computer Coupling of Phase Diagrams and Thermochemistry, 28, 15 (2004).

47. M. T. Farmer, B. W. Spencer, and R. W. Aeschlimann, "Liquidus/Solidus and Zr Solubility Measurements for PWR and BWR Core Melt Compositions," OECD Workshop on Ex-Vessel Debris Coolability, Karlsruhe, Germany, November 15-18, 1999.

48. M. T. Farmer, R. W. Aeschlimann, D. J. Kilsdonk, and B. W. Spencer, "Results of MACE Test M3b Posttest Debris Characterization," EPRI/ACEX-TR-C32 (2000).

49. D. R. Bradley, "Modeling of Heat Transfer Between Core Debris and Concrete," ANS Proc. 1988 National Heat Transfer Conf., Houston, Texas USA, July 24-28, 1988.

50. K. R. Robb and M. L. Corradini, "Ex-Vessel Corium Coolability Sensitivity Study with CORQUENCH Code," Proc. of NURETH-13, ANS, Sept. 27-Oct. 2, Kanazawa, Japan, paper N13P1290 (2009).

51. R. Gencheva, A. Stefanova, P. Groudev, M. Cranga, V. Tyrpekl, J. Duspiva, B. Kujal, G. Lele, and B. Chatterjee, "Investigation of Some Phenomena and Parametrical Studies on VVER1000 MCCI," $6^{\text {th }}$ European Review Meeting on Severe Accident Research (ERMSAR-2013), Avignon, France, October 2-4, 2013. 